(Aus dem physiologischen Institut der Universität Jena.)

\title{
Chemische und mikroskopische Untersuchungen über den Fetttransport durch die Darmwand bei der Resorption.
} Von

A. Noll.

(Hierzu Tafel XI und XII.)

Inhaltsverzeichnis.

Einleitung. . . . . . . . . . . . . . . 208

Der Resorptionsweg des mikroskopisch nachweisbaren Fettes. . . . . 210

I. Die Verteilung des Fettes in der Schleimhaut anf Epithel und Abführ-

wege. (1. Versuchsreihe) . . . . . . . . . . . . . 214

A. Bestimmung des Fettgehaltes durch Extraktion mit Petroläther . . 216

Der Fettgehalt . . . . . . . . . . . . 218

Der Fettgehalt in Rücksicht auf das Aussehen der Chylusgefässe . 220

Der Gehalt der Schleimhaut an Trockensubstanz . . . . . . . . 221

B. Die Verteilung des Fettes im mikroskopischen Präparat . . . . . 221

C. Zusammenfassung . . . . . . . . . . . . . . . . . 224

II. Der Chemismus des Fetttransportes. . . . . . . . . . . . . 227

A. Bestimmung der freien Fettsäure im Petrolätherextrakt und des nach Verdauen des Rückstandes noch extrahierbaren Fettes. (2. Versuchsreihe). ................. . . 2 . . . . . . . . . . . 230

Die freie Fettsäure . . . . . . . . . . . . . . . . 232

Das nach Verdauen extrahierbare Fett . . . . . . . . . 234

B. Unterscheidung von Fett, Fettsäure und Seife im mikroskopischen

Präparat. (3. Versuchsreihe) . . . . . . . . . . . 236

Schlussbetrachtungen . . . . . . . . . . . . . . 243

In der vorliegenden Arbeit habe ich untersucht, wie sich das aus dem Darminhalt resorbierte Nahrungsfett auf seinem Durchgang durch die Wand des Dünndarms verhält, wenn man Kaninchen grössere Mengen von Olivenöl oder Triolein in den Magen einführt.

Ich berühre hier nicht die Frage, wie das Fett aus dem Darminhalt in die Darmschleimhaut übertritt. Meine Untersuchungen betreffen 
vielmehr lediglich das Schicksal des Fettes erst von dem Augenblick an, wo es von der Darmwand aufgenommen ist, und sind vornehmlich auf folgende Punkte gerichtet:

1. Wie ist das Fett zu verschiedenen Zeiten der Resorption in den Geweben und Bahnen der Schleimhaut verteilt?

2. Wie vollzieht sich der Chemismus des Fetttransports?

Hierbei geht man am besten von der vollständig gesicherten Beobachtung aus, dass nach reichlicher Fettzufuhr beim Tier, und zwar wie die bisherigen Untersuchungen lehren bei fast allen untersuchten Tieren, zwei ganz charakteristische sichtbare Merkmale zu erkennen sind, nämlich ein hoher Fettgehalt der Zotten und ein bedeutender Fettreichtum des Chylus. Der Fettgehalt der Zotten auf der Höhe der Resorption dokumentiert sich durch ein gedunsenes Aussehen der weisslichen Schleimhaut, und derjenige der Chylusgefässe im Mesenterium durch die milchig-weisse Färbung ihres Inhalts.

Geht man nun von diesen beiden experimentell lejeht zu erzeugenden sichtbaren Erscheinungen aus, so hat man zu entscheiden, wie sich zu verschjedenen Zeiten die Fettmengen auf das Epithel und Stroma der Zotten und andererseits auf die Chylusbahnen verteilen, und in weleher Beziehung das Fett an beiden Orten zueinander steht. Diese Frage ist bisher noch nicht systematiseh untersucht worden.

Was die chemische Seite des Vorganges betrifft, so hatte ich in einer früheren Arbeit beim Frosch zeigen können, dass die Fetttröpfehen in den Epithelzellen stets sogenanntes Neutralfett sind, sei es dass Triglyzeride, Fettsäure oder Seife verfüttert waren. Ob dies Fett auf dem weiteren Transport noch Veränderungen erleidet, und ob sich irgendwo in der Schleimhaut Fettsäure und Seife fiudon, ist nicht bekannt. Man weiss nur durch äbereinstimmende Untersuchungen einiger Autoren, dass sich im Chylus, selbst nach Fütterung von Fettsäure, in der Hauptsache stets Neutralfett findet. Danit ist aber nicht gesagt, dass vorher in der Schleimhaut nicht eine Spaltung und nochmalige Synthese erfolgt. An diese Möglichkeit ist um so mehr zu denken, als noch ganz unklar ist, wie sonst das Fett aus den Epithelzellen herausgelangt. Auf diesen letzteren Punkt haben mit Recht die Histologen besonderen Nachdruck ge- 
legt. Es wäre also zu entscheiden, ob sich in der Darmschleimhaut nur Neutralfett oder auch Fettsäure und Seife findet.

Wenn man die Fragen in dieser Weise histologisch präzisiert, so liegt es auf der Hand, dass man ausser rein chemischen Methoden auch das Mikroskop zu Hilfe nehmen muss. So habe ich bei meinen Untersuchungen nicht nur durch die Extraktion im Grossen Fettbestimmungen ausgeführt, sondern auch im mikroskopischen Schnittpräparat die Lokalisation des Fettes im Gewebe festgestellt und es mikrochemisch zu analysieren versucht.

In der ersten Versuchsreihe wurde der Fettgehalt grösserer Darmabsehnitte durch Extraktion mit Petroläther quantitativ bestimmt und auf den jeweils schon makroskopisch erkennbaren Fettgehalt der Zotten und der Chylusbahnen bezogen. Ausserdem wurden Stückchen derselben Därme histologisch verarbeitet zur genaueren Lokalisation des Fettes im Epithel, Zottengewebe und Abführwegen.

In der zweiten Versuchsreihe wurde der Gehalt des Petrolätherextrakts an freier Fettsäure bestimmt und ferner geprüft, wie viel Fett sich nach Verdauen des Rückstandes noch findet.

In der dritten Reihe versuchte ich mikrochemisch den qualitativen Nachweis von Neutralfett, Fettsäure und Seife im Schnittpräparat.

Auf diese Weise glaube ich eine Reihe sicherer Befunde zur Lösung der gestellten Fragen beibringen und eine begründete Auffassung über die Art des Fetttransportes durch die Gewebe der Dünndarmschleimhaut äussern zu können.

\section{Der Resorptionsweg des mikroskopisch nachweisbaren Fettes.}

Die Widersprüche, welche eine Zeitlang bezüglich des Weges herrschten, den das mikroskopisch nachweisbare Fett in der Darmschleimhaut einschlägt, sind heute grösstenteils als gelöst $\mathrm{zu}$ betrachten.

Dies gilt in erster Linie von der Beteiligung des Zottenepithels. Es lässt sich mit Bestimmtheit sagen, dass die Epithelzellen in Fällen ergiebiger Fettresorption Fetttröpfehen enthalten. Offenbar hängt es von der zugeführten Fettmenge $a b$, ob man Fetttröpfehen im Epithel antrifft oder nicht. Dies geht schon aus der Arbeit von Letzerich ${ }^{1}$ ) hervor, wenn auch sonst seine Schilderungen nicht

1) Letzerich, Über die Resorption der verdauten Nährstoffe (Eiweisskörper und Fette) im Dünndarm. Virchow's Arch. Bd. 37 S. 232. 1866. 
mehr durchaus zutreffend sind; ferner hat Preusse ${ }^{1}$ ) dies beim Frosch bemerkt, und später äusserte R. Heidenhain ${ }^{2}$ ) die nämliche Auffassung. In welchem Maasse sich die Zellen mit Fett beladen können, ersieht man sehr gut aus den Abbildungen von $\mathrm{Kreh}^{3}$ ), Nicolas${ }^{4}$ ), Reuter $\mathrm{r}^{5}$ ). Die Anreicherung des Fettes vollzieht sich in der Darmepithelzelle nach Altman $\mathrm{n}^{6}$ ) and $\mathrm{Kreh}^{7}$ ), ebenso wie nach Metzner's ${ }^{8}$ ) und nach Arnold's ${ }^{9}$ ) Beobachtungen auch an anderen Zellen, unter wesentlicher Beteiligung der Zellgranula. Im allgemeinen findet sich das Fett zunächst in der Überkernzone, später aber, wie schon $\mathrm{Ei} \mathrm{me}{ }^{10}$ ) beobachtete, auch in dem tieferen Zellabschnitt. Bemerkenswert ist, dass gewöhnlich nicht alle Zellen derselben Zotte den gleichen Fettgehalt zeigen, in der Regel sind die an der Zottenspitze liegenden Zellen die gefülltesten. Diese Anfüllung des Epithels mit Fetttropfen ist die erste mikroskopisch sicher nachgewiesene Erscheinung bei der resorbierenden Tätigkeit der Schleimhaut.

Der nächste Ort, an dem Fett, wenn auch nicht von allen Autoren, so doch mit Sicherheit nachgewiesen ist, sind die Spalten zwischen den Epithelzellen. Über die Frage aber, wie das Fett dorthin gelangt, geben die Ansichten auseinander. Während Watne $y^{11}$ )

1) Preusse, Die Fettresorption im Dünndarm. Arch. f. wissensch. und prakt. Tierheilk. Bd. 11 S. 175. 1885.

2) R. Heidenhain, Beiträge zur Histologie und Physiologie der Dünndarmschleimhaut. Pflüger's Arch. Bd. 43 Suppl. S. 82. 1888.

3) Krehl, Ein Beitrag zur Fettresorption. Arch. f. Anat. (u. Physiol.) 1890 S. 97.

4) Nicolas, Recherches sur l'épithélium de l'intestin grêle. Intcrnat. Monatsschr. f. Anat. u. Physiol. Bd. 8 S. 1. 1891.

5) Reuter, Ein Beitrag zur Frage der Darmresorption. Anat. Hefte Bd. 21 S. 121. 1903.

6) Altmann, Die Elementarorganismen usw., 2. Aufl. Leipzig 1894.

7) Krehl, l. c.

8) Metzner, Über die Beziehungen der Granula zum Fettansatz. Arch. f. Anat. (u. Physiol.) 1890 S. 82.

9) Arnold, Weitere Beispiele granulärer Fettsynthese. Anat. Anz. Bd. 24 S. 389.1908.

10) Fimer, Zur Fettresorption und zur Entstehung der Schleim- und Eiterkörperchen. Virchow's Arch. Bd. 38 S. 428. 1867. - Eimer, Die Wege des Fettes in der Darmschleimhaut bei seiner Resorption. Virchow's Arch. Bd. 48 S. 119.1869.

11) Watney, The minute Anatomy of the Alimenty Canal. Philos. Transact. R. Soc. London vol. 166 part II p. 451. 1876. 
meinte, dass es direkt aus dem Darminhalt stamme, und Kischensky ${ }^{1}$ ) dies auch neuerdings für neugeborene Katzen annimmt, leiten es die meisten Autoren von dem Epithelfett ab. Was in diesem Falle die Art seines Austritts aus den Zellen betrifft, so ist in den letzten Jahren, soweit ich sehe, nur Wuttig ${ }^{2}$ ) der Meinung gewesen, es trete korpuskulär aus, andere aber fassen den Austritt so auf, dass er in Lösung geschehe. Die Schwierigkeit beruht darin, dass man den Vorgang selbst nicht sehen kann. Wenn nun das Fett in die interepithelialen Spalten gelangt ist, so sind es wieder zunächst feine Tröpfchen, wie sie Reuter an Quersehnittsbildern des Rattendarms am überzeugendsten abbildet. Man hat den Übertritt des Epithelfettes zottenwärts auch als "innere Sekretion" bezeichnet, eine Bezeichnung, die aber $\mathrm{Oppel}^{3}$ ) mit Recht für unzutreffend erklärt. Auf einen für die Beurteilung dieser interepithelialen Fetttröpfehen wichtigen Punkt hat zuerst v. Basch ${ }^{4}$ aufmerksam gemacht. v. Basch denkt nämlich an die Möglichkeit, dass intra vitam diese Tröpfchen durch "Regurgitation" aus dem Zotteninnern zurückbefördert seien, da er bei künstlicher Injektion in die Blutoder Chylusbahn unter stärkerem Druck die Injektionsmasse zwischen die Epithelzellen gelangen sah. Auch R. Heidenhain ${ }^{5}$ ) bält einen derartigen Vorgang für zutreffend. Nach Heidenhain aber würde er erst während der Fixierung durch Kontraktion der Zotte erfolgen, also nicht intra vitam, in der Weise etwa, wie v. Basch eine andere Erscheinung, nämlich ein Extravasieren von Fett zwischen Epithel und Zottenstroma sich erklärte. Als Beweis führt Heidenhain an, dass er bei Tieren mit muskellosen Zotten die Fetttröpfchen zwischen den Zellen nie gesehen habe. In neuester Zeit schliesst sich $\mathrm{Köster}^{6}$ ) dieser Erklärung an, weil er die interepitheliale Fettanbäufung nur da sah, wo das Zottenstroma vom

1) Kischensky, Zur Frage über die Fettresorption im Darmrohr usw. Beiträge zur pathol. Anat. u. allgem. Pathol. Bd. 32 S. 197. 1902.

2) Wuttig, Experimenteile Untersuchungen über Fettaufnahme und Fettablagerung. Beiträge zur pathol. Anat. u. allgem. Pathol. Bd. 37 S. 378.1905.

3) Oppel, Ergebnisse d. Anat. u. Entwicklungsgesch. Bd. 12 S. 99.

4) v. Basch, Die ersten Chyluswege und die Fettresorption. Sitzungsber. d. Wiener Akad., mathem.-naturwissensch. Kl. Bd. 62 Abt. 2 s. 617. 1870.

5) l. c.

6) G. Köster, Fettresorption im Darm und Gailenabsonderung nach Fettdarreichung. Leipzig 1908. (Verlag Klinkhardt). 
Epithel abgelöst war und sich die Fetttröpfchen keilförmig, mit der Spitze darmlumenwärts, zwischen die Zellen vordrängten. Nach diesen Autoren würde also ein histologisches Kunstprodukt vorliegen. Auf der anderen Seite gibt Kischensky ${ }^{1}$ ) an, dass auch dann sich Fett zwischen den Epithelzellen findet, wenn der Fettreichtum im Stratum proprium der Zotten relativ gering ist. Ich will hier sehon erwähnen, dass auch bei meinen Versuchen gerade in Fällen, wo wenig Fett im Zotteninnern war, die Tröpfehen sich zwischen deu Epithelzellen zahlreich fanden und hei maximaler Füllung der Zottenbahnen dort fehlen konnten. Wie dem auch sei, ob die Tröpfchen rückwärts aus der Zotte oder aber aus den Epithelzellen dorthin gelangen mögen, so sind jedenfalls die Spalten, in denen sie liegen, die Strasse, auf der das Fett von den Epithelzellen in das Innere der Zotte sich bewegen muss, ein Weg, den natürlich auch diejenigen gelten lassen müssen, nach deren Meinung das Fett mit Umgehung der Epithelzellen aus der Darmhöhle direkt in die Zotte gelangt.

Die Anwesenheit des Fettes innerhalb des Bindegewebes der Zotte ist ebenfalls erwiesen. Wie sich seine Bahn zu den histologischen Bestandteilen des Gewehes genauer verhält, braucht hier nicht erörtert zu werden, weil diese Frage für unsere Zwecke nicht wesentlich ist. Es sei nur angeführt, was $R$. Heidenhai ${ }^{2}$ ) darüber im Jahre 1888 schrieb: „Innerhalb des Zottenparenchyms bewegt sich das Fett, abgesehen von den geringen durch gefrässige Leukocyten aufgenommenen Mengen nur in den pericellulären mit Flüssigkeit erfüllten Räumen, welche durch die Bälkchen des bindegewebigen Stromanetzes unvollkommen gegeneinander begrenzt werden." Es sei hier auch nicht der Streit berührt, ob die Spalten, welche das Fett im Zottenparenchym passiert, in offener Kommunikation mit dem zentralen Chylusgefäss stehen oder nicht. Wichtiger ist für uns die Feststellung, dass das Fett weiterhin ausschliesslich in den Chylusgefässen der Zotten, der Drüsenschicht und der Submukosa, und nicht in der Blutbahn zu sehen ist ${ }^{3}$ ). Abbildungen von

1) l. c.

2) I. c. 8.93 .

3) Die Beobachtung Eysolt's (Inaugural-Dissertation. Kiel 1885), welcher ebenso, wie vor ihm schon $\mathrm{Bruch}$, in den Blutkapillaren der Zotten Fett in feinster Emulsion beschrieb, tist von R. Heidenhain für fehlerhaft erklärt worden. In neuerer Zeit hat nun noch Kischensky (l. c.) Fett in der Blutbahn, und zwar bei einer jungen Katze gefunden. 
fetterfülten Chylusbahnen finden sich zahlreich in der Literatur, z. B. schon bei $\mathrm{Funke}^{1}$ ), Watne ${ }^{2}$ ), Kirschensky ${ }^{2}$ ), Köster ${ }^{2}$ ). Letzterer beschreibt den Inhalt nach Behandlung mit Flemming scher Lösung als bestehend aus mehr oder weniger intensiv geschwärzten Tropfen von verschiedener Grösse und mattgrauer, homogener Inhaltsmasse und meint, wie ich glaube mit Recht, dass die grossen Fetttropfen erst sekundär aus kleinen und vielleicht erst bei der Fixierung entstanden seien.

Soweit dürfte im ganzen Klarheit herischen über den vom Fett eingeschlagenen Weg. Etwas schwieriger dagegen ist es, die Bedeutung der Lymphzellen für den Fetttransport zu würdigen. Die wesentliche Rolle, welche ihnen $\mathrm{Zaw}$ aryk in ${ }^{3}$ ) und auch Schäfer ${ }^{4}$ ) beigemessen haben, trifft sicherlich nicht $\mathrm{zu}$, wenn auch richtig ist, dass sie während der Fettresorption zahlreicher sich finden als in der nüchternen Schleimhaut. Für die Fälle intensiver Resorption, von denen hier gehandelt wird, kommen sie jedenfalls im Vergleich zu den geschilderten Bahnen, wie auch Wi eme $\mathrm{r}^{5}$ ) und He ide $n$ ha i ${ }^{2}$ ) meinten, nur nebenher in Betracht. ob sie unter physiologischen Verhältnissen grössere Bedeutung haben, wäre noch zu entscheiden.

Für die folgende Darstellung empfiehlt es sich, da wo es auf die genauere Lokalisation nicht ankommt, das in der Epithelschicht liegende Fett dem gesamten Fett der tieferen Schleimhautpartien gegenüberzustellen. Ich werde das erstere auch kurz als "Epithelfett", das übrige als das „Fett der Ausführwege" bezeichnen.

\section{Abschnitt.}

\section{Die Verteilung des Fettes in der Schleimhant anf Epithel} und Abfïhrwege. (1. Versuchsreihe.)

$\mathrm{Zu}$ diesen Versuchen dienten acht Kaninchen. Die Verdauungszeit betrug $2^{1 / 4}, 5,7^{1 / 2}, 9^{1 / 2}, 10,12^{1 / 2}, 14$ und $16^{1 / 2}$ Stunden.

1) Funke, Beiträge zur Physiologie der Verdauung. Zeitschr. f. wissensch. Zoologie Bd. 6 S. 307.1855.

2) l. c.

3) Zawarykin, Über die Fettresorption im Dünndarm. Pflüger's Arch. Bd. 31 S. 231. 1883.

4) Schäfer, On the part played by amoeboid cells in the process of intestinal absorption. Internat. Monatsschr. f. Anat. Bd. 2 S. 6. 1885.

5) Wi emer, Über den Mechanismus der Fettresorption. Pflüger's Arch Bd 33 S. 515. 1884. 
Sämtliche Kaninchen dieser wie auch der folgenden Reihen hatten 36-48 Stunden lang vor der Öleingabe kein Futter bekommen, damit in dieser Richtung die gleichen Bedingungen herrschten. 20 cem Olivenöl wurden mit der Schlundsonde in den Magen gegeben. Bestimmte Zeit danach wurde das Tier durch Kopfschlag getötet. Nach sofortiger Eröffnung der Bauchhöhle schnitt ich dann den Darm heraus. Zu den Versuchen der ersten Reihe wurde dieser in der folgenden Weise verarbeitet.

Es wurde derjenige Abschnitt des Dünndarms aufgesucht, welcher nach dem Aussehen der mesenterialen Chylusgefässe die deutlichsten Resorptionserscheinungen darbot, und nur dieser Teil wurde weiterbehandelt. Den Versuchen dieser Reihe liegen also ausschliesslich resorbierende Abschnitte zugrunde, und die für den Fettgehalt gefundenen Zahlen geben annähernd den höchstmöglichen Fettgehalt eines Teiles der gesamten Dünndarmschleimhaut in der betreffenden Stunde an. In diesem Sinne sind die Zahlen untereinander zu vergleichen.

Von der Darmwand wurden zunächst Stückchen zur mikroskopischen Untersuchung in die Fixierungslösung gelegt. Dann erfolgte die Weiterbehandlung, welche auf S. 216 beschrieben ist. Zum Schluss wurde der Magen eröffnet und nachgesehen, ob er ausser dem stets vorhandenen festen Inhalt auch noch Öl enthielt.

Der Darminhalt war fast in allen Fällen im oberen Alsschnitt flüssig, oft schleimig und manchmal grünlich gefärbt und enthielt stellenweise weiche bräunliche Beimengungen. In dem unteren Abschnitt war er fester, kotähnlich. Niemals sah ich emulgiertes Öl darin. Im Falle Nr. 8 war eine Schlinge und im Falle Nr. 11 der ganze obere Teil leer.

Der braune, ziemlich trockene Mageninhalt reagierte auf Lackmus sauer. Im Fall Nr. 7 fand sich ziemlich viel sauer reagierende Flüssigkeit, bei Nr. o viel Gas, welches die Wandung stark anfgebläht hatte. Nur bei diesem Tiere sah ich Öl, bei den anderen Tieren dagegen nicht oder nur wenige dem Mageninhalt beigemengte Fetttropfen.

Nach diesen Befunden wird man sagen dürfen, dass die $20 \mathrm{ccm}$ Öl für die Tiere nicht zuviel waren, denn Magen und Darm bewältigten sie offenbar leicht. 
A. Bestimmung des Fettgehalts durch Extraktion mit Petroläther.

Der zur Bestimmung genommene Dünndarmabschnitt, dessen Länge im einzelnen Fall $100-175 \mathrm{~cm}$ betrug, wurde von oben bis unten eröffnet und auf Fliesspapier ausgebreitet. Sodann wurde die Schleimbant mit destilliertem Wasser unter-sanftem Streichen mit dem Finger von anhaftendem Darminhalt gereinigt, bis sie sauber erschien. Nun wurde die Schleimhaut mit Fliesspapier trocken getupft, mit einem Skalpell von der Muskelhaut abgeschabt und in einer Porzellanschale gesammelt und gewogen. Die Wägung ergab das feuchte Gewicht. Danach wurde sie in der Schale zunächst auf ganz mässig erwärmtem Wasserbad, dann über Schwefelsäure im Vakuum bis zur Gewichtskonstanz getrocknet, in der Reibschale fein zerrieben und zur Bestimmung des Trockengewichts abermals gewogen. Das trockene Pulver wurde alsdann mit Petroläther (Kahlbaum) im Soxhlet-Apparat vollständig extrahiert. Nach Verdunsten des Petroläthers wurde der Rückstand von neuem in Petroläther aufgenommen, filtriert, getrocknet und gewogen.

Das extrahierte Fett stellte in den meisten Fällen und zwar stets dann, wenn die Schleimhaut sebr fettreich war, in der Hauptsache ein gelbliches Öl dar. Bei geringerem Fettgehalt erhielt ich eine salbenartige weissliche Masse mit unscharfem Schmelzpunkt. Letzterer lag dann etwas über $20^{\circ}$, denjenigen des Fettes eines nüchternen Tieres bestimmte ich zu $35-41^{\circ}$.

Die bei der Extraktion in den Petroläther übergehenden Fettsubstanzen, nämlich Neutralfett, Fettsäure, Lecithin und andere Lipoide brauchen hier nicht weiter unterschieden zu werden. Ich bezeichne sie im ganzen als "Fett". Seife wird vom Petroläther im Gegensatz zum Äthyläther nicht extrahiert. Frank und Ritter ${ }^{1}$ ) halten es aber für möglich, dass Seifen bei Gegenwart von Fettsäure in den Petroläther übergehen. Nachdem ich in der zweiten Versuchsreihe gefunden hatte, dass stets etwas, allerdings nicht viel freie Fettsäure sich im Extrakt findet, habe ich auch selbst nachgeprüft, ob bei den hier in Betracht kommenden Fettsäuremengen tatsächlich Seife vom Petroläther aufgenommen wird. Zu dem Zwecke nahm ich Olivenöl und Ölsäure in dem gefundenen Ver-

1) O. Frank und Ad. Ritter, Einwirkung der überlebenden Dünndarmschleimhaut auf Seifen, Fettsäure und Fette. Zeitschr. f. Biol. Bd. 47 S. 251. 1906. 
hältnis, löste sie in Pretoläther und setzte $0,2 \mathrm{~g}$ Seife hinzu, die ich aus Olivenöl durch Verseifung nach Kossel und Obermüller dargestellt hatte, und liess das Ganze einige Zeit auf dem Wasserbade. Nach dem Filtrieren und Verdunsten des Petroläthers resultierte in zwei derartigen Versuchen nur ein vollständig klares Öl, und die Wägung eroab keine Gewichtszunahme. Danach halte ich es für ausgeschlossen, dass bei den geringen Mengen Fettsäure, wie sie in meinen Versuchen vorliegen, Seife in den Petroläther übergeht.

In den num mitzuteilenden Protokollen sind angegeben: Das Aussehen der Damuschleimhaut und der Chylusgefässe, las Gewicht der Schleimhant und ihr Fettgehalt, letzterer ausgedrückt in Prozent der trockenen Schleimhaut. Die Fälle sind nach der Verdaungszeit geordnet, vorangestellt sind drei nüchterne Tiere, die ebenfalls 36 Stunden vor dem Tode ohne Futter geblieben waren.

Versuch Nr. 1. Kaninchen, männl., $2150 \mathrm{~g}$ schwer, nüchtern. Gewicht der Schleimhaut, feucht, $15 \mathrm{~g}$, nach dem Trocknen $2,0395 \mathrm{~g}=13,56 \%$ Trockensubstanz. Fettgehalt $0,1020 \mathrm{~g}=5,01 \%$.

Versuch Nr. 2. Kaninchen, männl., $1700 \mathrm{~g}$ schwer, nüchtern. Gewicht der schleimhaut, feucht, 12,5 g, getrocknet $1,9744 \mathrm{~g}=15,79 \%$ Trockensubstanz. Fettgehalt $0,111 \mathrm{~g}=5,66^{\circ} \%$.

Versuch Nr. 3. Kaninchen, weibl., $1850 \mathrm{~g}$ schwer, nüchtern. Schleimhut, feucht, $20 \mathrm{~g}$, getrocknet $3,3004 \mathrm{~g}==16,50 \%$ Trockensubstan $\%$. Fettgehalt $0,1570 \mathrm{~g}=4,76 \%$.

Versuch Nr. 4. Kaninehen, weibl., $2^{1 / 4}$ stunden nach Eingabe von $20 \mathrm{~cm}$ Olivenöl getötct. Schleimbaut strichweise weisslich. Genommen $125 \mathrm{~cm}$ Dünndarm. Schleimhaut, fencht, $8,8 \mathrm{~g}$, trocken $1,5460 \mathrm{~g}==17,57 \%$ Trockensubstan $z$. Fettgehalt $0,1720 \mathrm{~g}=11,12 \%$.

Versuch Nr. 5. Kaninchen, männl., $1520 \mathrm{~g}$ schwer. Nach 5 Stunden getötet. Schleimhaut weiss. Chylusgefässe des Mesenteriums mit etwas fetthaltigen Inhalt. Genommen $140 \mathrm{~cm}$ Dünndarm. Gewicht der Schleimhaut, feucht, $8,7 \mathrm{~g}$, trocken $1,6857 \mathrm{~g}=19,37 \%$ Trockensubstanz. Fettgehalt $0,3664 \mathrm{~g}=21,74 \%$.

Versuch Nr. 6. Kaninchen, weibl., $2100 \mathrm{~g}$ schwer. Nach $7^{1 / 2}$ Stunden getötet $(17,5 \mathrm{ccm}$ Öl). Schleimhaut deutlich weiss. Chylusgefässe des Mesenteriums milchig weiss. Genommen $140 \mathrm{~cm}$ Dünndarm. Schleimhaut, feucht, $12,1 \mathrm{~g}$, trocken $2,3997 \mathrm{~g}=19,39 \%$ Trockensubstanz. Fettgehalt $0,7595 \mathrm{~g}=$ $\therefore \rightarrow+46 \%$.

Versuch Nr. 7. Kaninchen, weibl., $2000 \mathrm{~g}$ schwer. Nach 91/2 Stunden getötet. Schleimhaut weiss. Chylusgefässe des Mesenteriums und der Darmwand stark milchig. Genommen $100 \mathrm{~cm}$ Dünndarm. Schleimhaut, feucht, 10,5 g, trocken $1,86 \% 9 \mathrm{~g}=17,80 \%$ Trockensubstanz. Fettgehalt $0,2415 \mathrm{~g}=12,91 \%$. 
Versuch Nr. 8. Kaninchen, weibl., $2300 \mathrm{~g}$ schwer. Nach 10 Stunden getötet. Schleimhant weiss. Chylusgefässe des Mesenteriums und der Darmwand milchig. Gewicht der feuchten Schleimhaut $9,5 \mathrm{~g}$, nach dem Trocknen $1,8477 \mathrm{~g}=$ $19,45 \%$ Trockensubstanz. Fettgehalt $0,3418 \mathrm{~g}=18,49 \%$.

Versuch Nr. 9. Kaninchen, männl., 1900 g schwer. Nach 121/2 Stunden getötet. Schleimhaut weiss und gedunsen. Chylusgefässe des Mesenteriums und des Darms stark milchig. Genommen $175 \mathrm{~cm}$ Dünndarm. Schleimhaut, feucht, $12 \mathrm{~g}$, trocken $2,6040 \mathrm{~g}=21,70 \%$ Trockensubstanz. Fettgebalt $0,8104 \mathrm{~g}=$ $31,12 \%$.

Versuch Nr. 10. Kaninchen, weibl., $2500 \mathrm{~g}$ schwer, nach 14 Stunden getötet. Schlєimhaut nur im oberen Abschnitt weiss. Chylusgefässe allenthalben milchig. Genommen $130 \mathrm{~cm}$ Dünndarm. Gewicht, feucht, $6 \mathrm{~g}$, trocken $1,0921 \mathrm{~g}=$ $18,20 \%$ Trockensulstanz. Fettgehalt $0,2280 \mathrm{~g}=20,88 \%$.

Versuch Nr. 11. TKaninchen, weibl., $2000 \mathrm{~g}$ schwer, nach $16^{1 / 2}$ Stunden getötet. Schleimhaut nirgends weiss. Chylusgefässe des Mesenteriums und stellenweise in der Darmwand milchig. Genommen $132 \mathrm{~cm}$ Dünndarm. Schleimhaut, feucht, $6,8 \mathrm{~g}$, trocken $1,2068 \mathrm{~g}=17,75 \%$ Trockensubstanz. Fettgehalt $0,1264 \mathrm{~g}=10,47 \%$.

Zur besseren Übersicht sind die Zahlen für den Gebalt an Trockensubstanz und an Fett in der folgenden Tabelle nochmals zusammengestellt.

\begin{tabular}{|c|c|c|c|}
\hline Nr. & $\begin{array}{l}\text { Stunden nach } \\
\text { Eingabe des Öls }\end{array}$ & $\begin{array}{c}\text { Gehalt der } \\
\text { Schleimbaut an } \\
\text { Trockensubstanz }\end{array}$ & $\begin{array}{c}\text { Gehalt der } \\
\text { trockenen Schleim- } \\
\text { l baut an Fett }\end{array}$ \\
\hline $\begin{array}{l}1 \\
2 \\
3\end{array}$ & $\begin{array}{c}\text { nüchtern } \\
n \\
"\end{array}$ & $\begin{array}{l}13,56 \% \\
15,79 \% \\
16,50 \%\end{array}$ & $\begin{array}{l}5,01 \% \\
5,66 \% \\
4,76 \%\end{array}$ \\
\hline $\begin{array}{r}4 \\
5 \\
6 \\
7 \\
8 \\
9 \\
10 \\
11\end{array}$ & $\begin{array}{ll}2^{1 / 4} & \text { Stunden } \\
5 & " \\
7^{1 / 2} & " \\
9^{1 / 2} & " \\
10 & " \\
12^{1 / 2} \quad " \\
14^{1 / 2} \quad " \\
16^{1 / 2} \quad "\end{array}$ & $\begin{array}{l}17,57 \% \\
19,37 \% \\
19,33 \% \\
17,80 \% \\
19,45 \% \\
21,70 \% \\
18,20 \% \\
17,75 \%\end{array}$ & $\begin{array}{l}11,12 \% \\
21,74 \% \\
32,46 \% \\
12,91 \% \\
18,49 \% \\
31,12 \% \\
20,88 \% \\
10,47 \%\end{array}$ \\
\hline
\end{tabular}

\section{Der Fettgehalt.}

Bei den drei nüchternen Tieren beträgt der Fettgehait zwischen $4,76 \%$ und 5,66\% vom Gewicht der getrockneten Schleimhaut.

In allen Fällen nach Eingabe von Olivenöl ist eine erhebliche Zunahme des Fettgehalts gefunden worden. in den ersten 8 Stunden (Nr. 4-(i) zeigt sich mit zunehmender 
Verdauungszeit ein kontinuierlicher Anstieg. Von da ab sind die Zahlen zunächst schwankend. Während nach $9^{1 / 2}$ und 10 Stunden (Nr. 7 und 8) verhältnismässig niedrige Werte erscheinen, findet sich nach 121/2 Stunden wieder ein sehr hoher Fettgehalt. In den beiden letzten Fällen (Nr. 10 und 11) ist der Fettgehalt nach 14-17 Stunden im Vergleich zu den höchsten Werten gering, so dass er in der 17. Stunde kaum noch so hoch ist wie in der 3. Stunde.

Beim Vergleich der Zahlen untereinander ist aber zu beachten, dass es sich jedesmal nur um ein einziges Tier handelt. Individuelle Eigentümlichkeiten bei der Fettresorption sind ohne weiteres zuzugeben. So könnten sich die stark abweichenden Zahlen der Fälle 7, 8, 9 durch eine individuell verschiedene Schnelligkeit in der Verdauung und Aufsaugung des Öls erklären. In der Tat zeigte die mikroskopische Untersuchung, dass bei Nr. 7 das Fett sich noch in der Phase der Anreicherung befand; hier war also offenbar die Aufnahme langsam. Fall Nr. 8 dagegen befand sich in einem weiter vorgeruckten Stadium. Hier kann der Höhepunkt bereits überschritten gewesen sein. Bei $\mathrm{Nr}$. 9 handelt es sich sicherlich wieder um eine Verzögerung im Ablauf der Vorgänge, so dass hier erst in der 13. Stunde ein Fettgehalt wie etwa bei Nr. 6 in der 8. Stunde angetroffen wird. Was die beiden letzten Fälle (Nr. 10 und 11) betrifft, so ist auf Grund der mikroskopischen Befunde mit Sicherheit zu sagen, dass in der Fettaufnahme der Höhepunkt überschritten war.

Bei Beurteilung der absoluten Fettmengen ist zu beachten, dass bei den resorbierenden Tieren in den Zahlen auch dasjenige Fett, welches sio im nüchternen Zustande haben, mit inbegriffen ist. Um die wirklich resorbierten Mengen zu finden, müsste man eine Umrechnung vornehmen. Dies ist jedoch bei der vorliegenden Versuchsreihe nicht unbedingt nötig, weil die Zahlen in den einzelnen Fällen so weit voneinander differieren, dass sie trotz der erwähnten Ungenauigkeit die Verhältnisse im grossen Ganzen richtig wiedergeben. In der nächsten Reihe, wo es auf die absolute Menge der im Extrakt enthaltenen Fettsäure genauer ankommt, ist eine solche Umrechnung für die Fettsäure wie auch für das Gesamtfett geschehen.

Die Tabelle scheint mir den allgemein güligen Schluss zu gestatten, dass sich das Fettin den ersten Stunden in der Schleimbaut in beträchtlichem Masse 
anreichert, und dass es dann allmählich wieder schwindet, ohne dass das Maximum der Anhäufung länger bestehen bleibt.

\section{Der Fettgehalt in Rücksicht anf das Aussehen der Chylusgefässe.}

Wie oben in den Versuchsprotokollen angegeben ist, erschien erst bei dem Tier, welches fünf Stunden nach der Öleingabe getötet war, der Chylus etwas fetthaltig, während nach zwei Stunden dies noch nicht der Fall war. Um dies etwas auffallende Resultat der ersten Stunden durch weitere Beobachtungen zu stützen, habe ich noch andere Kaninchen nach $1 \frac{1}{2}, 2$ und $3^{3 / 4}$ Stunden auf das Verbalten ihrer Chylusgefässe geprüft. Aber in keinem Falle hatte der Chylus das charakteristische milchige Aussehen. Auch mikroskopisch fand sich in den Gefässen der Schleimhaut kein Fett. Es lässt sich also mit Bestimmtheit sagen, dass in meinen Versuchen der Chylus erst um die 5. Stunde einen für das Auge deutlichen Fettgehalt erreichte.

Je mehr dann der Fettgehalt der Schleimhaut steigt, um so mehr wächst auch der Fettgehalt des Chylus, die mesenterialen Gefässe treten dann als feine, weiss inizierte Bahnen selbst bei solchen Tieren hervor, deren mesenteriales Fettgewebe stark entwickelt ist. Es fällt nicht schwer, dann auch die Chylusgefässe der Darmwand von aussen deutlich hervortreten zu sehen. Dieser Zustand hält an, solange sich noch Fett in nennenswerter Menge aus der Schleimbaut extrahieren läst. Ja, es schien mir sogar, als wenn gerade in den spätesten Stadien (nach 14 und $16^{1 / 2}$ Stunden) die Injektion der Chylusgefässe am stärksten gewesen wäre.

Wenn man nun das Aussehen des Chylus mit dem auf dem Wege der Extraktion gefundenen Fettgehalt der Schleimhant vergleicht, so kommt man zu folgenden bemerkenswerten Frgebnissen:

1. Die Schleimhaut erreichte bereits einen nicht unbedeutenden Fettgehalt, bevor eine Abführung von Fett durch die Chylusbahnen sich erkennen liess.

2. Es folgt ein Stadium, in dem der Fettgehalt der Schleimhat weiter zunimmt, gleichzeitig nun auch die Fettabfuhr einsetzt, um in der Folge mehr und mehr anzusteigen. Letztere beginnt also nicht erst dann, wenn der Fettgehalt sein Maximum erreicht hat. 
3. Wenn in späteren Stunden der Fettgehalt sinkt, bleibt die Abfuhr auf der Höhe bestehen.

Diese Ergebnisse werden durch die mikroskopischen Befunde, wie gleich gezeigt werden soll, vollauf bestätigt.

\section{Der Gehalt der Schleimhant an Trockensubstanz.}

Es erübrigt, noch kurz auf die Zahlen der vorletzten Spalte der obigen Tabelle (S. 218) einzugehen.

Die Schleimhäute der nüchternen Tiere haben, wie die $\mathrm{Zu}^{-}$ sammenstellung ergibt, durchweg den geringsten Gehalt an Trockensubstanz. Während der Resorption fällt in allgemeinen ein hoher Gehalt an Trockensubstanz mit einem hohen Fettgehalt zusammen. Dies kann nur darauf beruhen, dass bei der Resorption Substanz angereichert wird, und die nächstliegende Erklärung wäre, es sei dies vor allem das aufgenommene Fett selbst. Es ist aber möglich, dass gleichzeitig auch noch Blutbestandteile in den Schleimhautgeweben zurückgehalten werden.

\section{B. Die Verteilung des Fettes im mikroskopischen Präparat.}

Die Fixierung der Darmstückehen geschah in Fle m ming'scher Lösung (4 Teile 2\% Osmiumsäure, 15 Teile $1 \%$ Chromsäure, 1 Teil Eisessig). Diese Lösung ist für den vorliegenden Zweck vollständig ausreichend. Da sie nämlich am nüchternen Darm, wie ich mich überzeugte, gar nicht oder höchstens ganz selten einmal in dem Epithel ein schwarzes Körnchen zeigt, an den resorbierenden Därmen dagegen in der ausgiebigsten Weise, wie die Abbildungen auf Tafel XI dartun, geschwärzte Fettmassen darstellt, so bringt sie gewiss alles zutage, was für die hier in Betracht kommende quantitative Schätzung des Fettgehaltes in Frage steht. Ich betone dies, weil zur Zeit von den pathologisehen Anatomen für den Fettnachweis die Fixierung mit Formol und folgende Färbung mit Sudan III oder Scharlach R. bevorzugt wird. Bei der Osmiummethode besteht nur die Gefahr, dass in Laufe der Einbettung osmiertes Fett wieder gelöst wird. Um in dieser Hinsicht keinen Fehler zu machen, habe ich in einigen Fällen von den fixierten I)armstückchen Gefriersehnitte angefertigt, bevor sie mit Alkohol in Berührung kamen. Die Bilder deckten sich aber dann mit denen der frischen Balsampräparate. Frst bei längerer Aufbewahrung in Kanadabalsam wurde osmiertes 
Fett extrahiert. Ich verwendete deshalb schliesslich reinen, ungelösten Balsam; in diesem sind die Präparate haltbar. Bemerkt sei noch, dass ich zur Einbettung meist Celloidin nahm, da der Äther-Alkohol keine lösende Wirkung hatte ${ }^{1}$ ). — Da beim nüchternen Tiere so gut wie keine Osmiumreaktion eintrat, fällt das fernere Bedenken fort, es könne nicht alles, was im Präparat schwarz ist, Fett sein. Ich halte es also auch für ausgeschlossen, dass nach meinen Präparaten auf zuviel Fett geschlossen werden kann.

Es fand sich folgendes:

Versuch Nr. 4. Sämtliche Zotten im Schnittpräparat haben geschwärztes Epithel, hauptsächlich im Bereich der Zottenspitzen. Die Tropfen sind meist klein und liegen vornehmlich in der Überkernzone. Kein Fett im Zottengewebe and den Abführwegen.

Versuch Nr. ō. Schwärzung des Epithels allenthalben nur mässig stark. Die Fetttropfen von mittlerer Grösse. Stellenweise in den Chylusgefässen der Submukosa geschwärzter Inhalt.

Versuch Nr. 6. Sämtliche Zotten enthalten meist bis an den Grund hin . schwarzes Epithel. Die Tropfen liegen in der Überkernzone reichlicher als in der Unterkernzone und sind dort grösser. In den Chylusgefässen, besonders in denen der Submukosa, grauer und schwarzer Inhalt.

Versuch Nr. 7. Alle Zotten mit schwarzem Epithel. Die Fettropfen sind vornehmlich in den Zellen der Zottenspitzen, aber auch an den Rändern, hier jedoch nicht so gross und zahlreich. Die Tropfen finden sich in der Überkernzone reichlicher als in der Unterkernzone. Fettmassen auch im Zottenstroma. In den zentralen Chylusgefässen grauer, feinkörniger Inhalt und grössere schwarze Tropfen. Desgleichen in den Chylusgefässen der Submukosa und des Mesenteriums.

Versuch Nr. 8. An allen Zotten zeigt das Epithel ausgedehnte Resorption. Intensive Schwärzung des Fettes. Im Zotteninnern viel Fett. In den Chylusgefässen ebenfalls reichliche geschwärzte Fettmassen.

Versuch Nr. 9. Am Gefrierschnitt erscheint der Epithelsaum tief dunkelbraunn. Grosse Tropfen im Epithel sichtbar. In den Gefässen der Submukosa schwarze Inhaltsmassen. Am Paraffinschnitt: Schwärzung des Epithels vornehmlich in den oberen Abschnitten der Zotten. Dortselbst sehr grosse Tropfe,n vor allem in der Überkernzone. Schwarzer Inhalt in den Chylusgefässen.

Versuch Nr. 10. Gefrierschnitt: Etwas Schwärzung im Epithel, jedoch kaum noch in der Überkernzone. In den Abführwegen viel Fett. Celloidinschnitt: Epithel wie im Gefrierschnitt. Desgleichen im Zottenparenchym und in den Chylusbahnen viel Fett.

Versuch Nr. 11. Epithel fast frei von Fett. Sehr viel geschwärzte Fettmassen im Zottenstroma und in den abführenden Wegen.

1) Bei der Herstellung der Präparate wurde ich in freundlicher Weise von Herrn cand. med. Kowl er unterstützt. 
Das bemerkenswerteste Ergebnis der mikroskopischenUntersuchung besteht darin, dass sich zwei entgegengesetzte Zustände in der Schleimhaut vorfinden können. Ersterenfalls liegt das Fett ausschliesslich oder vorwiegend im Epithel; so in den ersten Stunden nach der Öleingabe. Andernfalls ist es vorwiegend in den Abführwegen, nämlich in den letzten Stunden. Übergänge zwischen beiden Zuständen kommen vor, so dass sowohl Epithel als auch Chylusbahnen fetthaltig sind.

Des genaueren ergibt sich, dass das Fett der Epithelzellen sowohl hinsichtlich der Verteilung über die Zotten als auch bezüglich der Grösse der einzelnen Tropfen von kleinen Anfüngen innerhalb ler ersten Stunden an mehr und mehr zunimmt. Bevor die Fettinfiltration des Epithels d as Höhestadium erreich hat, zeigt sich schonetwas Fett in den Chylusgefässen an beiden Orten erfolgt sodann eine Zunahme. Dann beginnt das Fett aus dem Epithel zu schwinden, aber die Chylusbahnen bleiben his zuletzt stark gefüllt. Diese Resultate, insbesondere den Mang e fetthaltigen Inhalts der Chyluswege in den ersten Stunden, habe ich noch in anderen Fällen, die oben nicht mit angeführt sind, bestätigt gefunden.

Die Art, in der dic allmähliche Zunahme des Fettgehalts der Epithelzellen dem Auge sich darbietet, ist bereits histologisch genauer untersucht, seitdem Altmann ${ }^{1}$ ) und $\mathrm{Krehl}^{1}$ ) die Beteiligung der Zellgranula erkannt hatten. Aber auch über die zeitlichen Beziehungen des Auftretens des Chylusfettes zum Epithelfett finden sich in der Literatur schon Angaben. Richtig schildert v. Basch ${ }^{1}$ ) nach Beobachtungen an Igeln, Hunden, Katzen und Ratten, dass man Zottenepithel, Zottensubstanz und zentralen Zottenraum gleichzeitig oder auch die beiden letzteren allein fetthaltig findet, oder dass die Verteilung des Fettes innerhalb ein und derselben Zotte variieren kann bei gleichzeitig wechselndem Fettgehalt des Epithels. Auch auf Übergange zwischen diesen Formen weist v. Basch hin. Auch Kischensky ${ }^{1}$ ) sah den Füllungszustand des Epithels und des Strat. proprium wechselnd und führt dies auf verschiedene Perioden in der Resorption zurück. Zuletzt ist $\mathrm{K}$ öster ${ }^{1}$ ) auf diese Verhältnisse zurückgekommen. Bei denjenigen Tieren, die Ölemulsion mit Pankreonzusatz bekommen hatten, konnte der Zentralkanal Fett

1) 1. c. 
enthalten, während Epithel und Stroma davon frei waren, oder das Stroma war fetthaltig bei fettfreiem Epithel.

$\rightarrow$ Wie sich in meinen Versuchen das Fett in den einzelnen Phasen in der Scbleimhaut verteilt, illustrieren die Abbildungen 1-4 auf Taf. XI. Fig. 1 stammt von Fall 4. Man sieht das für das frühe Resorptionsstadium charakteristische Bild: Gesebwärzte Fetttropfen nur im Epithel, und zwar vorwiegend an den Zottenspitzen; die Tröpfchen sind noch klein. Fig. 2 entspricht bezüglich des Fettgehaltes des Epithels dem Höhestadium. Die Zellen nicht nur der Zottenspitzen, sondern auch der Seiten sind erfüllt mit zum Teil sehr grossen Tropfen, so dass der Epithelsaum einen tiefschwarzen Kontur darstellt. In Fig. 3 (Nr. 7) ist das Übergangsstadium zu sehen. Das Epithel enthält stellenweise noch Fetttropfen, in einer Zotte (rechts) sogar noch reichlich, in den beiden anderen vornehmlich nur im Grunde und ferner im Zottenstroma. Die stark erweiterten zentralen Chylusgefässe enthalten Fetttropfen. Es kommt hier leider nicht mehr die ursprünglich im frischen Präparat deutlich gewesene grauschwarze Färbung des übrigen Inhalts der Chylusgefässe zum Ausdruck. In Fig. 6, wo das ursprüngliche Bild erhalten ist, sieht man den Inhalt und erkennt ausserdem auch genauer die Fetteinlagerungen im Epithel und Zottenstroma. In Fig. 4 (Nr. 10) ist das Epithel ziemlich fettarm, dafür findet sich viel Fett in den tieferen Gewebsschichten. Vor allem an den schräg durchsehnittenen Zotten sind die zentralen Partien schwarz, der Epithelsaum dagegen hell, und viel Fett liegt in den zentralen Chylusbahnen. Genauer noch sieht man in Fig. 7, die vom selben Tier stammt, dass hier nur Reste von Fetttropfen in der epithelialen Zone liegen, und dass Zottengewebe und Chylusbahnen voll davon sind.

Um auch anschaulich zu machen, wie die Gefässe der Submukosa in den späteren Stadien von Fett erfüllt sein können, füge ich noch Abbildung 5 bei. Die Fixierung geschah hier mit Formol, die Färbung mit Sudan III. Alles, was in der Figur schwarz ist, ist rot gefärbtes Fett des Präparats. Dieser Fall ist der zweiten Versuchsreihe entnommen.

C. Zusammenfassung.

Ich stelle die Ergebnisse der Fettextraktionen mit den mikroskopischen Befunden zusammen. Es ergibt sich folgendes. 
Das Fett, welches die Darmschleimhaut im nüchternen Zustand enthält, wird durch Fle m ming' sche Lösung nicht geschwärzt. Es kann sich hier vielleicht um Lipoide handeln.

Bezüglich der resorbierenden Därme herrscht eine gute Übereinstimmung insofern, als dem mit blossem Auge wahrnehmbaren Fettgehalt der Zotten und Chylusgefässe in jedem einzelnen Falle ein gleicher mikroskopisch nachweisbarer Fettgehalt des Epithels und der Abführwege entspricht. Vor allem ergibt ein Vergleich, dass sich im Schnittpräparat erst dann Fett in dem Chylus findet, weun der Chylus der mesenterialen Gefässe das charakteristische milehweisse Aussehen hat. Nimmt man hierzu nun die Zahlen für den Fettgehalt der Tabelle I, so sieht man, dass die ansteigenden und hohen Zahlen imwesentlichen das Epithelfett, die fallenden Zahlen aber im wesentlichen das Fett der Abführwege anzeigen. Wenn, wie bei Nr. 11, die Schleimhaut nicht mehr weiss aussieht und mikroskopisch im Epithel kaum noch Tropfen vorhanden sind, dann drückt die Zahl fast nur das Chylusfett aus. Je mehr dann das Fett durch die Lymphe abgeführt wird, um so mehr muss sich der Fettgehalt der Schleimhaut dem des nüchternen Tieres wieder nähern.

Es besteht also eine unverkennbare Beziehung zwischen Epithel- und Chylusfett. Wie dies Verbältnis aufzufassen ist, bedarf jedoch noch einer näheren Erörterung.

Einfach lägen die Dinge, wenn die Epithelzellen sich zunächst ad maximum füllten und dann erst das Fett in den Chylus weitergäben. Dem ist aher nicht so. Denn, wie wir sahen, lässt sich Fett im Chylus bereits dann nachweisen, wenn das Epithel noch in zunehmender Resorption begriffen ist. Es bleibt nun zu entscheiden, ob das in diesem frühen Stadium auftretende Chylusfett doch von dem Epithelfett oder etwa direkt aus dem Fett des Darminhalts auf dem Wege interepithelialer Resorption stammt. Gewiss ist gegen die letztere Möglichkeit ein direkter Gegenbeweis nicht ohne weiteres zu bringen. Denn wollte man auch anfübren, dass man in den ersten Stunden Fetttröpfchen nie zwischen den Epithelzellen sieht, so muss man andererseits doch zugeben, dass auch im Zottenstroma, das unter allen Umständen das Fett passieren muss, um in die Chylusbahn zu gelangen, zu dieser Zeit auch kein mit Osmium sich schwärzendes Fett liegt. Vollkommen aussehliessen lässt sich also dieser Vorgang einstweilen nicht. Aber man kann mit ziemlieher 
Bestimmtheit dennoch sagen, dass in der Hauptsache das erste sichtbare Chylusfett wirklich aus dem Epithel kommt. Aus folgendem Grunde: Es lässt sich nämlich das verhältnismässig späte Auftreten des Fettes im Chylus nur durch die Einschaltung eines cellularen Prozesses in denganzen Resorptionsvorgangerklären. Sein Hineingelangen in die Chylusbahn muss von der Tätigkeit der Epithelzellen unmittelbar abhängen. Allein schon die mikroskopischen Befunde zwingen zu dieser Annahme. Ferner aber fällt auch eine chemische Tatsache mit ins Gewicht. Bei der Annahme einer regen interepithelialen Resorption von emulgiertem Fett nämlich müsste man die mit der heutigen Auffassung in direktem Widerspruch stehende Voraussetzung machen, dass das Fett ungespalten in die Darmwand einträte. Denn, wie ich noch zeigen werde, stellt das interepitheliale Fett keine Seife und keine freie Fettsäure dar.

Hieraus ergibt sich folgende Auffassung: Während noch die Fettropfen in den Epithelzellen sich vergrösseru, wird auch schon Fett aus den Zellen fortgeschafft. Demnach hätte man zwei Vorgänge in den Zellen zu berücksichtigen. Erstens die Aufspeicherung eines Teils des von den Zellen resorbierten Fettes in Tropfenform und zweitens die Weiterbeförderung eines anderen Teils, der die Zelle schneller passiert. Der letztere Vorgang wäre der wesentlichere, wenn er auch histologisch nicht so hervortritt wie der andere, die Ansammlung der Tropfen aber ein Parallelvorgang, der nur die stark gesteigerte Zelltätigkeit anzeigt. Die beiden Vorgänge würden nebeneinanderher verlaufen, bis nichts mehr aus dem Darm aufgenommen wird. Alles Fett, das sich dann noch in den abführenden Gewebsspalten und -bahnen findet, muss ausschliesslich aus den Fettropfen der Zellen stammen. Dieser den sichtbaren Resorptionsvorgang beschliessende Vorgang liegt den Bildern z. B. in Fig. 4 zugrunde, wo das Epithel fast leer, die Abführwege aber noch sehr fetthaltig sind. Ausschliesslich auf dieses Stadium beziehen sich auch die oben zitierten Angaben von v. Basch, $\mathrm{K}$ ischensky und Köster.

Die Fetttropfen des Epithels haben bereits seitens einiger Autoren eine äbnliche Beurteilung gefunden, wie ich sie gebe. Dass sie als Ausdruck gesteigerter Resorption aufgefasst wurden, ist oben schon angeführt. Dass sie aber auch hierbei nicht die wesentlichste 
Phase des Vorganges markieren, ist schon von Histologen klar ausgesprochen worden. Es ist vor allem Oppel gewesen, der des öfteren betonte, „dass die während der Resorption in der Darmepithelzelle auftretenden Fetttröpfehen eine dem eigentlichen Wesen der Resorption mehr fernstehende Bedeutung besitzen und als Aufspeicherungen aufzufassen sind, wie sie ja auch in anderen Zellen, z. B. den Fettzellen, unter günstigen Ernährungsverhältuissen beobachtet werden" (Ergebn. d. Anat. u. Entwicklungsgeschichte IX, S. 135). Die in der Epithelzelle sich abspielenden chemischen Vorgänge fasse ich allerdings anders auf als Oppel, worauf ich noch zurückkomme. Schon früher hatte sich $\mathrm{R}$. Heidenhain ${ }^{1}$ ) folgendermaassen geäussert: "Freilich kommt es vor, dass man im Zottenstroma Fett antrifft, während dasselbe in den Epithelzellen fehlt, dann nämlich, wenn die Nahrung nur geringe Fettmengen enthielt. Der Grund liegt wohl darin, dass bei mässiger Aufnahme die Epithelzellen das Fett in dem Maasse, als sie es aufnehmen, auch weiter befördern, so dass es zu einer Anhäufung in ihrem Innern nicht kommen kann." Mit diesen Worten wird eine Analogie angedeutet zu dem Verhalten der sezernierenden Nierenzellen, welche bei einer Überschwemmung der Blutbahn mit injiziertem Farbstoff in ihren Granula den Farbstoff aufspeichern, da sie ihn nicht ebenso schnell weiterzugeben vermögen (Ergebn. d. Physiol. VI, S. 25).

\section{Abschnitt.}

\section{Der Chemismus des Fettransportes.}

Bestimmungen des Mengenverhältnisses von freier Fettsäure und Nentralfett in der Darmschleimhaut sind bisher nur von Moor ${ }^{2}$ ) und von $\mathrm{Sait}^{3}$ ) in dem Ätherextrakt von Hundedärmen gemacht worden. Moore bestimmte nach Eingabe von Olivenöl die Fett- und Fettsäuremenge nicht nur in der Schleimhaut, sondern auch in der Lymphe, die er an denselben Tieren aus den mesenterialen Chylusgefässen gewann. In einem Falle fand er 6 Stunden nach Eingabe

1) Pflüger's Arch. Bd. 43. Suppl. \$. 87.

2) Moore, On the Synthesis of Fat accompanying Absorption from the intestine. Proceed. of the Royal Soc. vol. 72 p. 134. 1903.

3) Saito, Studien über die Spaltung und Resorption des Nahrungsfettes. Inauguraldissertation. Würzburg 1905. 
von $100 \mathrm{~g}$ Olivenöl in der Schleimhaut $15,7 \%$, in der Lymphe $4,7 \%$ freie Fettsäure (vom Gesamtfett), in einem zweiten Falle 7 Stunden nach Eingabe von $50 \mathrm{~g}$ Olivenöl $35,4 \%$ resp. 3,9\% freie Fettsäure. Saito hat in der grösseren Zahl seiner Versuche die ganze Darmwand, also auch die Muskelhaut, mit extrahiert. Die Schleimhaut allein wurde aber auch in zwei weiteren Fällen verarbeitet. Diese beiden lieferten im Mittel für die obere Hälfte des Dünndarms, und zwar ihren oberen Abschnitt 41,57\%, ihren unteren Abschnitt 39,80\% und für die untere Hälfte $33,65 \%$ freie Fettsäure (als Ölsäure). Ausserdem bestimmte Saito, wieviel Fettsäure sich noch nach Ansäuern des Ätherextrakts fand. Verfüttert wurde Schweinefett, dem Ölsäure beigemengt war. Beide Autoren fanden also ziemlich viel Fettsäure in der Schleimhaut, in der Lymphe dagegen Moore wesentlich weniger.

Mehr Bearbeitung hat der Chylus des Ductus thoracicus gefunden. Hier galt es hauptsächlich zu entscheiden, wie seine Zusammensetzung nach Verfüttern von freier Fettsäure sich verhielt. In den meisten Experimenten erhielten die Hunde deshalb Fettsäuren. Alle Autoren, I. $\mathrm{Munk}^{1}$ ), Lebedeff ${ }^{2}$ ), v. Walther ${ }^{3}$ ), $\mathrm{Frank}^{4}$ ), fanden dann stets mehr Neutralfett als Fettsäure. Lebedeff, welcher Leinölsäure verfütterte, fand sogar fast nur Neutralfett und keine Fettsäure. Munk dagegen, dessen Bestimmungen sich auf verschiedene Verdauungsstunden beziehen, nur 6-17 mal so viel Fett als Fettsäure, Frank um die 9. und 10. Stunde noch mehr Fettsäure.

In einem Versuch, bei dem ein Hund mit der Nahrung ausser Fettsäure $(54,5 \mathrm{~g})$ auch Neutralfett $(45,5 \mathrm{~g})$ erhalten hatte, bestimmte v. Walther die in 100 Teilen Chylus enthaltene Menge sauren Fettes zu $0,09 \mathrm{~g}$ und neutralen Fettes zu $1,96 \mathrm{~g}$, also etwa $4,4 \%$ Fettsäure. Diese Zahl stimmt gut überein mit den von Moore

1) I. Munk, Arch. f. (Anat. u.) Physiol. 1879 S. 371. Virchow's Arch. Bd. 80 S. 10. Ferner: Arch. f. (Anat. u.) Physiol. 1883 S. 273. Virchow's Arch. Bd. 95 S. 407.

2) Lebedeff, Studien über Fettresorption. Arch. f. (Anat. u.) Physiol. 1883 S. 488.

3) v. W alther, Zur Lehre von der Fettresorption. Arch. f. (Anat. u.) Physiol. 1890 S. 329.

4) Frank, Zur Lehre von der Fettresorption. Arch. f. (Anat. u.) Physiol. 1894 S. 297. Ferner Zeitschr. f. Biol. Bd. 36 S. 568. 1898. 
erbaltenen Werten $(4,7 \%$ bzw. $3,9 \%$ Fettsäure in der mesenterialen Lymphe).

Seife fand sich bei den erwähnten Versuchen, soweit darauf geachtet wurde, im Chylus während der Fettresorption kaum oder gar nicht mehr als sonst.

Auch menschlicher Chylus wurde untersucht. In dem bekannten Fall von I. Munk und Rosenstein ${ }^{1}$ ), wo eine Chylusfistel am Unterschenkel eines Mädchens bestand, betrug der Gehalt des ausfliessenden Chylus an Fettsäure nach Eingabe von Olivenöl, das $6,4 \%$ freie Ölsäure enthielt („Lipanin“), 2,4\%. In einem Fall von Chylurie fand Erben ${ }^{2}$ ) nach Darreichung von gemischter Kost den Fettsäuregehalt gleich $1,68 \%$ des Ätherextrakts. In dem Falle von I. Munk und Rosenstein wie auch in einem Falle von Minkowski ${ }^{3}$ ), wo chylöser Ascites untersucht werden konnte, fand sich übrigens, wie beim Hund, nach Fettsäureeingabe Neutralfett im Chylus.

Da ich bei meinen Kaninchen nur Olivenöl nahm, kommen von den mitgeteilten Tierversuchen streng genommen vergleichshalber nur diejenigen in Betracht, bei denen nicht oder nicht ausschliesslich freie Fettsäuren gegeben wurden, also diejenigen Moore's, Saito's und der eine Versuch von v. Walther. Bei diesen war im Chylus stets wenig Fettsäure, im Mittel etwas über $4 \%$ des Gesamtfettes. In der Darmschleimhaut dagegen war der Fettsäuregehalt erheblich höher. Aus der Zunahme des Neutralfettes auf dem Wege von der Darmschleimhaut nach den Chylusgefässen folgert Moore, dass in der Schleimhaut eine Synthese erfolgt. Die in ihr noch nicht vollständig gebundene Fettsäure wäre es dann, welche sie reicher an Fettsäure macht als die abfliessende Lymphe.

Was den Ort der Synthese betrifft, so habe ich durch mikroskopische Reaktionen am Froschdarm zeigen können, dass jedenfalls die Epithelzellen befähigt sind, aus Fettsäure Neutralfett zu bilden ${ }^{4}$ ).

Man kann nach alledem im Hinblick auf den Chemismus des

1) I. Munk und Rosenstein, Zur Lehre von der Resorption im Darm, nach Untersuchungen an einer Lymph(Chylus-)fistel beim Menschen. Virchow's Arch. Bd. 123 S. 230. 1891.

2) Erben, Die chemische Zusammensetzung menschlichen Chylusfettes. Zeitschr. f. physiol. Chemie Bd. 30 S. 436, 1900.

3) Minkowski, Arch. f. experim. Pathol. (Schmiedeberg) Bd. 21.

4) Arch. f. (Anat. u.) Physiol. 1908 Suppl. S. 145. 
Fetttransportes mit zwei Tatsachen rechnen: 1. der Fähigkeit des Zottenepithels, Fett zu synthetisieren, und 2. der Tatsache, dass während der Resorption von Fett in der Darmschleimhaut und im Chylus mehr Neutralfett als freie Fettsäure, im Chylus sogar ganz erheblich mehr sich findet.

Welche chemischen Vorgänge sich nun in den Epithelzellen abspielen, in welcher Form das Fett aus ibnen herauskommt und in die Chylusbahn gelangt, das sind die wesentlichsten Fragen, die die beiden folgenden Versuchsreihen beantworten sollen.

In der nächsten Versuchsreihe wurde die Fettsäure im Petrolätherextrakt titrimetrisch bestimmt. Ferner habe ich noch die Rückstände der künstlichen Verdauung unterworfen und das alsdann noch extrahierte Fett gewogen ${ }^{1}$ ). Wenn auch von vornherein keine grossen Quantitäten solchen Fettes zu erwarten waren, so musste doch der Vollständigkeit halber nachgesehen werden, ob auch in dieser Beziehung Unterschiede zwischen nüchternen und resorbierenden Därmen bestehen.

In der letzten Versuchsreihe habe ich die mikrochemische Analyse des Fettes versucht.

A. Bestimmung der freien Fettsäure im Petrolätherextrakt und des nach Verdauen des Rückstandes noch extrahierbaren Fettes.

\section{(2. Versuchsreihe.)}

Zu diesen Versuchen dienten fünf Kaninchen, von denen eins $4^{1 / 2}$ Stunden, eins 5 Stunden, zwei weitere 8 Stunden und das letzte 12 Stunden nach Eingabe von $20 \mathrm{~cm}$ Öl getötet wurde. Zum Teil hatten die Tiere Olivenöl, zum Teil Triolein erhalten. Bei den beiden ersten Tieren (5. Stunde) rechnete ich nach den Resultaten der ersten Versuchsreihe darauf, das Fett in der Hauptsache im Epithel anzutreffen, bei den beiden folgenden (8. Stunde) erwartete ich es ausserdem auch schon in grösserer Menge in den Abführwegen, und im letzten Falle (nach 12 Stunden) musste das Epithel schon im wesentlichen entleert, dagegen gerade die Chylusbahn noch stark gefüllt sein. In der Tat lagen nach den Sektionsbefunden und nach

1) Vgl. die Arbeit von F. N. Schulz in Pflüger's Arch. Bd. 66 S. 145. 
der im letzten Falle angestellten mikroskopischen Untersuchung bei sämtlichen Tieren die erwarteten Stadien vor.

Bis zur Wägung des extrahierten Fettes verfuhr ich genau so wie in der ersten Versuchsreihe, nur mit der Änderung, dass ich, um eine während des Trocknens der abgeschabten Schleimbaut möglichenfalls eintretende Bilduno von freier Fettsäure durch Enzymwirkung $\mathrm{zu}$ verhindern, den herausgeschnittenen Darm sofort in toto für 10 Minuten in kochendes Wasser tat. Das gesamte extrahierte Fett wurde in Äther-Alkohol gelöst und unter Zusatz einiger Tropfen Phenolphthalein als Indikator zur Bestimmung der freien Fettsäure nit wässriger 1/10-Normal-Natronlauge titriert. Die Berechnung geschah auf Ölsäure.

Der in Petroläther unlösliche Rückstand wurde mit $100 \mathrm{ccm}$ Pepsin-Salzsäure im Thermostaten bei $39^{\circ} \mathrm{C} .24$ Stunden lang verdaut, die Flüssigkeit vom Ungelösten abgegossen und mit Petroläther ausgeschüttelt, das ungelöst Gebliebene getrocknet and im SoxhletApparat mit Petroläther wieder extrahiert. Nach Vereinigung beider Extrakte wurde dann das Fett gewogen.

$\mathrm{Zu}$ diesen fünf Versuchen nahm ich immer die Schleimhaut des ganzen Duodenums und Dünndarms, um bei den zu erwartenden geringen Fettsäurequantitäten möglichst viel Ausgangsmaterial zu haben. Da in der ersten Versuchsreihe nicht die ganzen Därme, sondern nur die jedesmal in stärkster Resorption befindlichen Dünndarmabschnitte gebraucht wurden, sind die Zahlen für den Gesamtfettgehalt in beiden Reihen nicht direkt vergleichbar. Naturgemäss müssen sie in der zweiten Reihe ceteris paribus niedriger ausfallen.

Ausserdem machte ich dieselben Bestimmungen auch an zwei nüchternen Tieren. Es sind dies die oben angeführten Tiere der Versuche Nr. 2 und 3.

Versuch Nr. 2. (Siehe oben.) Fettgehalt der Schleimhaut $=5,66 \%$. $0,1096 \mathrm{~g}$ des Fettes enthalten $0,0142 \mathrm{~g}$ Olsüure $=12,96 \%$. 1,8626 g des Rückstandes geben nach dem Verdanen noch $0,0789 \mathrm{~g} \mathrm{Fett}=4,23 \%$.

Versuch Nr. 3. (Siehe oben). Fettgehalt der Schleimhaut 4,76\%. $0,1548 \mathrm{~g}$ des Fettes enthalten $0,02486 \mathrm{~g}$ Olsäure $=16,06 \%$. 3,1039 $\mathrm{g}$ des Rückstandes geben nach der Verdauung noch $0,0880 \mathrm{~g}$ Fett $=2,83 \%$.

Versuch Nr. 12. Kaninchen, weibl., $1920 \mathrm{~g}$ schwer. 41/2 Stunden nach Eingahe von $20 \mathrm{~cm}$ Provenceröl getötet. Chylusgefässe des Mesenteriums nirgends milchigweiss. Im Magen keine Ansammlung von Öl. Gewicht der feuchten Schleimhant $13,5 \mathrm{~g}$, nach dem Trocknen 2,4654 g. Fettgehalt $0,2964 \mathrm{~g}=$ 
$12,02 \%$. Diese 0,2964 $\mathrm{g}$ Fett enthalten 0,02997 $\mathrm{g}$ Ölsäure $=10,11 \%$. 2,0136 g des Rückstandes geben nach der Verdauung $0,0715 \mathrm{~g}$ Fett $=3,55 \%$.

Versuch Nr. 13. Kaninchen, weibl., $2000 \mathrm{~g}$ schwer. 5 Stunden nach Eingabe von $20 \mathrm{ccm}$ Triolein getötet. Einzelne mesenteriale Chylusgefässe zeigen etwas milchigweisse Färbung. Im Magen etwas Öl. Gewicht der feuchten Schleimhaut $16 \mathrm{~g}$, nach dem Trocknen $3,2098 \mathrm{~g}$. Fettgehalt $0,7223 \mathrm{~g}=22,50 \%$. $0,7188 \mathrm{~g}$ dieses Fettes enthalten $0,036408 \mathrm{~g}$ Ölsäure $=5,06 \%$. 2,4798 $\mathrm{g}$ des Rückstandes geben nach der Verdauung noch $0,0450 \mathrm{~g}$ Fett $=1,81 \%$.

Versuch Nr. 14. Kaninchen, männl., $2100 \mathrm{~g}$ schwer, 8 Stunden nach Eingabe von $20 \mathrm{ccm}$ Provenceröl getötet. Mesenteriale Chylusgefässe deutlich fetthaltig. Im Magen kein Öl. Feuchte Schleimhaut $=20 \mathrm{~g}$, trocken $4,2513 \mathrm{~g}$. Fettgehalt $0,7856 \mathrm{~g}=18,48 \%$. $0,7830 \mathrm{~g}$ dieses Fettes enthalten $0,053742 \mathrm{~g}$ Ölsäure $=6,86 \%$. 2,0584 $\mathrm{g}$ des Rückstandes geben nach dem Verdauen noch 0,0592 g Fett $=2,88 \%$.

Versuch Nr. 15. Kaninchen, männl., $1850 \mathrm{~g}$ schwer, 8 Stunden nach Eingabe von $20 \mathrm{ccm}$ Triolein getötet. Mesenteriale Chylusgefässe deutlich fetthaltig. Im Magen kein Ol. Schleimhaut feucht $20 \mathrm{~g}$, trocken $3,7488 \mathrm{~g}$. Fettgehalt $0,7357 \mathrm{~g}=19,62 \% . \quad 0,7310 \mathrm{~g}$ dieses [Fettes enthalten $0,049728 \mathrm{~g}$ Ölsäure $=6,80 \%$. $2,8848 \mathrm{~g}$ des Pückstandes geben nach dem Verdauen noch $0,0854 \mathrm{~g}$ Fett $=2,96 \%$.

Versuch Nr. 16. Kaninchen, weibl, $2200 \mathrm{~g}$ schwer, 12 Stunden nach Eingabe von $20 \mathrm{ccm}$ Provenceröl getötet. Mesenteriale Chylusgefässe sehr fetthaltig. Desgleichen in den Gefässen der Darmwand milchweisser Chylus. Im Magen vereinzelte Öltropfen. Schleimhaut feucht $21 \mathrm{~g}$, trocken $4,2599 \mathrm{~g}$. Fettgehalt $0,6617 \mathrm{~g}=15,53 \%$. $0,6598 \mathrm{~g}$ dieses Fettes enthalten $0,03552 \mathrm{~g}$ Ölsäure $=$ , $38 \%$. 3,2682 g des Rückstandes geben nach dem Verdauen noch $0,0919 \mathrm{~g}$ Fett $=2,81 \%$.

Der Gehalt des Petrolätherextraktes an freier Fettsäure.

Die gefundenen Zahlen sind in der folgenden Tabelle untereinander geordnet.

Tabelle II.

\begin{tabular}{|c|c|c|c|}
\hline Nr. & $\begin{array}{l}\text { Stunden nach } \\
\text { Eingabe des Öls }\end{array}$ & $\begin{array}{l}1 . \\
\text { Ohne Verdauen ex- } \\
\text { trahiertes Fett in } \% \\
\text { der trockenein } \\
\text { Schleimhaut }\end{array}$ & $\begin{array}{l}2 . \\
\text { Darin freie } \\
\text { Fettsäure }\end{array}$ \\
\hline $\begin{array}{l}2 \\
3\end{array}$ & $\begin{array}{c}\text { nüchtern } \\
" n\end{array}$ & $\begin{array}{l}5,66 \% \\
4,76 \%\end{array}$ & $\begin{array}{l}12,96 \% \\
16,06 \%\end{array}$ \\
\hline $\begin{array}{l}12 \\
13 \\
14 \\
15 \\
16\end{array}$ & \begin{tabular}{ccc} 
nach & \multicolumn{3}{l}{$4 /$ a } & Stunden \\
$"$ & 5 & $"$ \\
$"$ & 8 & $"$ \\
$"$ & 8 & $"$ \\
$"$ & 12 & $"$
\end{tabular} & $\begin{array}{l}12,02 \% \\
22,50 \% \\
18,48 \% \\
19,62 \% \\
15,53 \%\end{array}$ & $\begin{array}{r}10,11 \% \\
5,06 \% \\
6,86 \% \\
6,80 \% \\
5,38 \%\end{array}$ \\
\hline
\end{tabular}

Die Zahlen der Spalte 1 zeigen den grössten Fettgehalt der ganzen Schleimhaut zwischen der 5. und 8. Stunde an. Hiervon 
entfallen nach dem makroskopischen Befund die 22,5\% der Nr. 13 fast ausschliesslich auf das Epithel; denn die mesenterialen Chylusgefässe enthielten in diesem Fall sehr wenig Fett. Bei den beiden nächsten Tieren bezeichnen die $18,48 \%$ und 19,62\% das Epithel- und Chylusfett. Nr. 12 und 16 stellen direkt entgegengesetzte Zustände dar. Ersterenfalls nämlich konnte nur Epithelfett, letzterenfalls fast nur Chylusfett sich im Extrakt finden.

Spalte 2 gibt die Fettsäuremengen an. Um diese Zahlen untereinander annähernd richtig vergleichen zu können, müsste man sie auf gleichen Gesamtfettgehalt umrechnen. Denn es ist ohne weiteres ersichtlich, dass sie durch einen Anstieg des Fettgehaltes der Schleimhaut heruntergedrückt werden und umgekehrt. Daher der anscheinend bedeutende Fettsäuregehalt der nüchternen Därme. Aber auch dann bliebe noch eine Ungenauigkeit, insofern als bei den resorbierenden Därmen der Fettsäuregehalt des nüchternen Zustandes in den Zahlen noch mitenthalten ist.

Es wurde deshalb folgende Umrechnung vorgenommen. Zunächst berechnete ich nach Nr. 2 und 3, wieviel Säure zu 100 Teilen fettfreier, nüchterner Trockenschleimhaut hinzukommt. Es sind im Mittel 0,78 Teile; ich nenne diesen Anteil kurz „Bestandsäure". Sodann berechnete ich für Nr. 12-16, wieviel Säure die resorbierende trockene fettfreie Schleimhaut (also Trockenschleimhaut weniger extrahiertem Fett) im ganzen addierte, und fand durch $\mathrm{Ab}$ zug der Bestandsäure von der berechneten Säuremenge die wirklich auf Resorption zurückzuführende Säure (Ölsäure). Die erhaltenen Zahlen gibt die folgende Tabelle in Prozent a uf 100 Teile fettfreier, trockener Schleimhaut an (Spalte 2).

Dieselbe Umrechnung habe ich hier auch für das Gesamtfett vorgenommen und die Werte in Spalte 1 der Tabelle angeführt.

Hiernach gestaltet sich die Sache folgendermaassen:

Tabelle III.

100 'Teile trockener fettfreier Schleimhaut haben aufgenommen:

\begin{tabular}{|c|c|c|c|c|}
\hline $\mathrm{Nr}$. & & & $\begin{array}{c}1 . \\
\text { Gesamttett }\end{array}$ & $\begin{array}{l}2 . \\
\text { Freie Fettsäure }\end{array}$ \\
\hline $\begin{array}{l}12 \\
13 \\
13 \\
15 \\
16\end{array}$ & $\begin{array}{c}\text { nach } \\
" \\
" \\
" \\
"\end{array}$ & $\begin{array}{cc}41 / 2 & \text { Stunden } \\
5 & " \\
8 & " \\
8 & " \\
12 & "\end{array}$ & $\begin{array}{cc}7,81 & \text { Teile } \\
22,39 & " \\
16,35 & " \\
18,01 & " \\
12,29 & "\end{array}$ & $\begin{array}{cc}0,57 & \text { Teile } \\
0,64 & n \\
0,74 & " \\
0,83 & n \\
0,19 & "\end{array}$ \\
\hline
\end{tabular}


Die Fettsäuremengen, welche infolge Resorption in der Scbleimhaut tatsächlich angereichert wurden, sind hiernach ausserordentlich gering. Sie erreichen bei weitem nicht die von Moore ${ }^{1}$ ) und von Saito ${ }^{1}$ beim Hund gefundenen Werte. In meinen Versuchen enthält die Schleimhant bei der Resorption etwa nur doppelt so viel Säure als im nüchternen Zustande.

Wenn man die Zahlen der Spalte 2 der Reihe nach durchgeht, so bemerkt man mit zunehmender Verdauungszeit einen kleinen Anstieg bis einschliesslich zur 8. Stunde. Der Anstieg ist aber zu gering, um irgend etwas Charakteristisches für dieses Stadium erkennen zu lassen. Man kann nur sagen, dass das Maximum des Fettsäuregehaltes sich dann fand, wenn die Abführung des Fettes durch die Lymphe in Gang gekommen war. Dass aber diese Fettsäure nicht im Chylusfett selbst enthalten ist, beweist zur Evidenz der Fall 16. Denn hier ist der Fettsäuregehalt niedrig, während gerade die Füllung der Chylusgefässe am stärksten war.

Wo findet sich nun denn die Fettsäure? - Ganz gewiss auch nicht in den sichtbaren Fettropfen des Epithels. Denn wäre dies der Fall, dann müssten die Anstiege im Fettsäure- und Gesamtfettgehalt bis zur 8. Stunde parallel gehen. Auch durch die Ergebnisse der mikrochemischen Untersuchung, die ganz übereinstimmen mit meinen früheren Beobachtungen am Froschepithel, ist diese Möglichkeit ein für allemal ausgeschlossen. Ebensowenig aber wie im Epithel, lässt sich nach der mikrochemischen Untersuchung die Fettsäure in die Tröpfehen zwischen den Epithelzellen oder wo sich sonst noch mikroskopisch nachweisbares Fett findet, lokalisieren. Daraus ergibt sich, dass sich diese Fettsäure dem histologischen Nachweis mit Osmiumsäure entzieht.

\section{Das nach kinstlicher Verdauung extrahierbare Fett.}

Wieviel Fett sich in den obigen, Versuchen nach Verdauen des nach der Petrolätherextraktion verbliebenen Rückstandes noch gewinnen liess, zeigt die folgende Tabelle.

1) 1. c. 
Chem. und mikroskop. Untersuchungen über den Fetttransport etc. 235

Tabelle IV.

\begin{tabular}{|c|c|c|}
\hline $\mathrm{Nr}$ & $\begin{array}{l}\text { Stunden nach Ein- } \\
\text { gabe des Öls }\end{array}$ & $\begin{array}{c}\text { Fett im verdauten } \\
\text { Räckstand }\end{array}$ \\
\hline $\begin{array}{l}2 \\
3\end{array}$ & $\begin{array}{c}\text { nüchtern } \\
y\end{array}$ & $\begin{array}{l}4,29^{\circ} / 0 \\
2,83^{\circ} / 0\end{array}$ \\
\hline $\begin{array}{l}12 \\
13 \\
14 \\
15 \\
16\end{array}$ & $\begin{array}{ccc}\text { nach } & 41 / 2 & \text { Stunden } \\
" & 5 & " \\
" & 8 & " \\
" & 8 & " \\
" & 12 & n\end{array}$ & $\begin{array}{l}3,55 \% \\
1,81 \% \\
2,88 \% \\
2,96 \% \\
2,81 \%\end{array}$ \\
\hline
\end{tabular}

Die Beurteilung dieser Zahlen ist einfach. Die Werte halten sich bei den resorbierenden Tieren innerhalb der Grenzen derjenigen der nüchternen oder liegen noch etwas tiefer (Nr. 13). Man kann hieraus wohl mit Sicherheit schliessen, dass alles resorbierte Fett, welches die Darmschleimhat passiert, in einer Form darin ist, die ohne weiteres in den Petroläther übergeht. Ausgeschlossen ist vor allem, dass etwa ein nennenswerter Anteil dieses Fettes in einer unlöslichen Eiweissverbindung ist. Was erst naəh künstlicher Verdauung sich extrahieren lässt, dürfte zu den zum Bestande der Schleimhaut gehörenden Lipoiden zu rechnen sein. Dieses Fett wäre also unabhängig von der Fettresorption und betrüge bis $4 \%$ und mehr der trockenen, fettfreien Schleimhaut.

Fs ist auch zu bedenken, dass es sich bei dieser Behandlungsweise um Abspaltung von Fettsäure aus Seife handeln kann. In der Tat fand sich in den Extrakten zwischen $70 \%$ und $85 \%$ freier Fettsäure. Um hierüber mehr Klarheit zu bekommen, habe ich noch folgenden Versuch gemacht.

$3 \mathrm{~g}$ Trockenrückstand von den Därmen der ersten Versuchsreihe wurden mit $20 \mathrm{ccm}$ destillierten Wassers verrührt. Nach dem Filtrieren, das übrigens schlecht ging, wurde ein abgemessenes Quantum des Filtrats mit der gleichen Menge 1\% iger Salzsäure versetzt, von der entstandenen Fällung abfiltriert, der Niederschlag mit Salzsäure ausgewaschen, getrocknet und mit Petroläther behandelt. Es fand sich $0,33 \%$ Fett. Unter der Voraussetzung, dass dies aus Seife entstandene Fettsäure war, würde der Versuch zeigen, dass das Mengenverhältnis von Seife zu Lipoiden ein sehr geringes wäre. Seife ist also bestenfalls sehr wenig vorhanden, was auch mit den bisherigen Befunden am Hundechylus vollständig übereinstimmt. 
B. Unterscheidung von Fett, Fettsäure und Seife im mikroskopischen Präparat.

(3. Versuchsreibe.)

Im Laufe der letzten Jahre sind einige Methoden angegeben worden, um Fettsubstanzen auf mikrochemischem Wege zu unterscheiden. Die Methode Fischlers ${ }^{1}$ ) erstreckt sich auf die Trennung von Neutralfett, Fettsäure und Seife, diejenige Rossi's ${ }^{2}$ ) auf den Nachweis von Fettsäure. Beide, wie auch eine Methode von Lorrain Smith und Mair ${ }^{3}$, welche auf Fettsäure und Cholesterin abzielt, sind Färbemethoden und werden am fixierten Gewebe angestellt.

Am Darmepithel selbst hat Rossi seine Methode angewandt. Er findet in demjenigen Abschnitt der Epithelzellen (beim Frosch), welcher an das Darmlumen stösst, die Reaktion auf Fettsäure positiv. Vergleicht man die Abbildungen Nr. 2 und 3 Rossi's mit den bekannten Osmiumbildern, so sieht man ohne weiteres, dass die Fettsäurereaktion im wesentlichen gerade denjenigen Raum freilässt, wo die Fetttropfen liegen sollen. Also auch diese Methode würde zeigen, dass die Fetttropfen selbst keine freie Fettsäure enthalten, dass aber da, wo das resorbierte Fett zunächst in die Zellen gelangt, freie Fettsäure in der Zelle vorhanden ist.

Kürzlich erschien noch eine vorläufige Mitteilung von F. W. Lamb ${ }^{4}$ ), in der über die Anwendung der Methode von Lorrain Smith und Mair am Darmepithel berichtet wird. Dass Fett der intracellulären Tropfen soll danach "desaturated " oder in Verbindung mit Cholesterin sein.

Die Methode, welche ich selbst benutzte, zielt direkt auf den Nachweis von Triolein, Ölsäure und ihre Salze ab.

Um Seife zu erkennen, hat man Schnitte nach Behandlung mit reiner $1 \%$ iger Osmiumlösung und solche nach Behandlung mit Flemming'scher Lösung miteinander zu vergleichen. Denn

1) Fischler, Zentralbl. f. allgem. Pathol. Bd. 15 S. 913.

2) G. Rossi, Sull' Assorbimento dei Saponi e degli Acidi grassi. Arch. di Fisiol. vol. 4 p. 429.1907.

3) Zit. nach Schmorl, Die pathologiseh-histologischen Untersuchungsmethoden, 5. Aufl., S. 145 .

4) F. W. Lamb, Some Observations on Fat Absorption. Journ. of Physiol. vol. 40 p. XXiii. Proceed. of the physiol. Soc. Febr. 1910. 
Osmiumsäure allein schwärzt nur das Öl und die Ölsäure, aber nicht Seife. Die Flemming'sche Lösung dagegen zerlegt vermöge ihres Gehaltes an Chrom-Essigsäure die Seife und schwärzt die dabei entstandene Ölsäure. Fine Mehrschwärzung im Flemming'schen Präparat kann also Seife anzeigen.

Um die Ölsäure vom Triolein zu unterscheiden, gehe ich von der zuerst von Altman ${ }^{1}$ ) gemachten Beobachtung aus, dass die Ölsäure-Osmiumverbindung in Alkohol löslich ist, die Triolein-Osmiumverbindung aber nicht.

Bereits früher habe ich dies differentialdiagnostische Moment beim Frosch verwendet. Am schärfsten stellt sich die Methode in folgender Weise dar. Tränkt man ein Stückchen Fliesspapier (A) mit Triolein und eins mit Ölsäure (B) und legt beide für 24 Stunden in 1\% ige Osmiumlösung, so kann man die Probe A 24 Stunden wässern und dann in steigenden Alkohol bringen oder aber nach nur kurzem Abspülen in Wasser direkt in 96\% igen Alkohol übertragen beide Male erfolgt keine Extraktion durch den Alkohol. Die Probe B hingegen verträgt zwar auch die Behandlung mit steigendem Alkohol nach vorhergehendem. 24 Stunden langem Wässern, aber wenn man sie nur kurz wässert und unmittelbar danach in den $96^{\circ} \%$ igen Alkohol legt, dann gibt sie dichte schwarze Wolken an den Alkohol ab. Die osmierte Ölsäure ist also unter diesen Verbältnissen, d. h. wenn die Alkoholbehandlung rasch erfolgt, unbeständig.

Wenn man nun osmierte Darmwand in dieser doppelten Weise behandelt - ich spreche der Einfachheit halber vom raschen und langsamen Alkoholverfahren - , so ist die Schwärzung, die sich nach dem raschen Verfahren im Präparat noch vorfindet, nicht durch freie Ölsäure bedingt, sondern muss auf der Gegenwart gebundener Ölsäure, also z. B. des Triglyzerids beruhen. In diesem Falle wird sie natürlich auch nach dem langsamen Verfahren vorbanden sein. Ist hingegen nach dem kurzen Verfahren weniger Schwärzung da als nach dem anderen Verfahren, oder auch gar keine, so handelt es sich bei dem gelösten Fett vielleicht um Ölsäure, jedenfalls nicht um Triolein. In diesem Falle muss aber die Schwärzung auf Gefrierschnitten, die man vor der Alkoholbehandlung anfertigt, vorhanden sein. Man kann also auf die eine oder andere Weise Ölsäure oder Triolein ausschliessen.

1) Altmann, Die Elementarorganismen usw. 2. Aufl. S. 118. 
Das Verfahren gestaltet sich demnach folgendermaassen: Man fixiert Stückchen in Osmiumsäure und solche in Flem ming'scher Lösung. Von den osmierten Stückchen fertigt man erstens Gefrierschnitte an und behandelt zweitens ein Stück nach dem rasehen und eins nach dem langsamen Verfahren. Von den FlemmingStücken würde es, um Seife zu fassen, genügen, wenn man nur die Gefriermethode und das langsame Verfahren einschlüge. Ich habe jedoch bei meinen Versuchen auch das andere Verfahren hinzugenommen und dabei ein unerwartetes Ergebnis erhalten.

Es wurden drei Kaninchen untersucht, vor denen jedes $20 \mathrm{ccm}$ Triolein nach 36 stündigem Fasten erhalten hatte. Das eine wurde nach 9 , das andere nach 12 , das dritte nach 14 Stunden getötet. Bei den beiden ersteren war das Epithel noch ziemlich fetthaltig, ausserdem enthielt auch der Chylus Fett. Beim letzteren war das Epithel schon ziemlich fettfrei, dafür aber viel Fett in den Abführwegen. Alle Fälle zeigen also das Fett da, wo es überhaupt sein kann, nur entsprechend der verschiedenen Verdauungszeit in verschiedener Verteilung.

Versuch Nr. 17. Kaninchen, männl., $1970 \mathrm{~g}$ schwer, 9 Stunden nach Eingabe von $20 \mathrm{~cm}$ Triolein getötet. Untersucht wurde eine Dünndarmschlinge, deren Schleimhaut weisslich war und deren mesenteriale Chylusgefässe milchigen Chylus enthielten. Je ein Stück Darm eingelegt in 1\% ige Osmiumsäurelösung und Flemming'sche Lösung,

1. Osmiumpräparat. Gefrierschnitt: Epithelsaum schwarz; im Zottenstroma keine Schwärzung, auch nicht in der Submukosa. Nur in zwei Gefässen innerhalb der Drüsenschicht etwas braungefärbter Inhalt.

Celloidinschnitt: a) nach 1/2 stündigem Wässern des Objektes und direkter Übertragung in $96 \%$ igen Alkohol: Intensive Schwärzung des Epithelfettes, besonders in der Überkernzone. Kleine schwarze Tröpfchen $z$ wischen den Epithelzejlen. Weder im Zottenstroma noch in der Submukosa osmiertes Fett. b) nach 24 stündigem Wässern des Objekts und Weiterbehandlung mit steigendem Alkohol: Dasselbe Bild wie bei a, nur findet sich in einem Chylusgefäss zwischen den Drüsenschläuchen braunschwarzer Inhalt.

2. Flemming-Präparat. Gefrierschnitt: Epithelsaum schwarz. In den Gefässen der Submukosa ziemlich viel schwarzer Inhalt.

Celloidinschnitt: a) nach dem raschen Alkoholverfahren: Epithelfett schwarz. Tröpfchen zwischen den Epithelzellen nicht so zahlreich wie in dem gleich behandelten Osmiumpräparat. Nur in einem Gefäss der Submukosa etwas grauer Inhalt, sonst nirgends. - b) Nach dem langsamen Alkoholverfahren: Im Epithel tiefschwarze Tropfen. Interepitheliale Tröpfchen vorhanden. Sowohl in den zentralen Chylusgefässen als auch in den tieferen Abführbahnen und den mesenterialen Chylusgefässen diffus schwarzgrauer Inhalt und schwarze Tropfen. 
Versuch Nr. 18. Kaninchen, männl., $1800 \mathrm{~g}$ schwer, 12 Stunden nach Eingabe von $20 \mathrm{ccm}$ Triolein getötet. Genommen eine Darmschlinge mit weisser Schleimhant und hochgradig fetthaltigem Chylus.

1. Osmiumpräparat. Gefrierschnitt: Schwärzung nur im Epithel.

Celloidinschnitt: a) nach dem raschen Alkoholverfahren: Fett in der Überund Unterkernzone des Epithels. Auch Fett zwischen den Epithelzellen. In dem zentralen Chylusgefäss einer Zotte grauer Inhalt. b) nach dem langsamen Verfahren: Epithel wie bei a. In ein em Gefäss der Submukosa diffus schwarzer, in einem andern grauer Inhalt.

2. Flemming-Präparat: Gefrierschnitt: Schwarze Färbung findet sich im Epithel, stellenweise im Zotteninnern und innerhalb der submukösen Chylusbahnen, hier reichlich.

Celloidinschnitt: a) nach dem schnellen Verfahren; Epithel schwarz, aber nicht in dem Maasse wie an dem Osmiumpräparat; das osmierte Fett scheint zum Teil extrahiert. Innerhalb der Zotten, zwischen den Drüsenschläuchen und in der Submukosa nur stellenweise schwärzliche Massen. Im Mesenterium ebenso. b) nach dem langsamen Verfahren: Fett des Epithels und interepitheliales Fett wie im Osmiumpräparat. In den Zottenchylusgefässen ziemlich zah̆lreiche schwarze Tropfen, desgleichen in den Gefässen der Submukosa und des Mesenteriums.

Versuch Nr. 19. Kaninchen, männl., $1820 \mathrm{~g}$ schwer, 14 Stunden nach Eingabe von $20 \mathrm{ccm}$ Triolein getötet. Aus der unteren Dünndarmhälfte, deren mesenteriale Chylusgefässe am fetthaltigsten sind, eine Schlinge genommen. Schleimbaut derselben nicht weiss.

1. Osmiumpräparat. Gefrierschnitt: Schwärzung nur im Epithelsaum.

Celloidinschnitt: a) nach dem schnellen Verfahren: Schwarze Tropfen nur in der Tiefe der Epithelschicht, nicht zahlreich. b) nach dem langsamen Verfahren: Die Tröpfchen des Epithels vornehmlich in der Unterkernzone; ganz vereinzelt etwas graue Masse im zentralen Chylusgefäss und in den submukösen Bahnen.

2. Flemming-Präparat. Gefricrschnitt: Kpithel wie im Osmiumpräparat. Ausserdem an vielen Stellen geschwärztes Fett innerhalb der Zotten, in den Gefässen der Submukosa und des Mesenteriums.

Celloidinschnitt: a) nach dem raschen Verfahren: Epithelzellen grösstenteils fettfrei. Unterhalb des Epithels vereinzelte Tröpfchen. Sonst nur vereinzelte schwarze Tröpfchen in den Bahnen der Submukosa. b) nach dem langsamen Verfahren: Im Epithel bedeutend mehr Fett als bei a. Fett zwischen den Epithelzellen, im Zottenstroma, den zentralen Chylusgefässen und den Babnen der Submukosa.

Un die Befunde übersichtlich zu machen, lasse ich eine Zusammenstellung folgen, in der angegeben ist, wo jedesmal im Schnitt und in welchem Maasse dort der Nachweis vom Fett gelang. Da eine genaue Lokalisation der Fetttröpfehen zwischen den Epithelzellen im Gefrierschnitt aus naheliegenden Gründen nicht möglich war, fallen hier die Angaben fort. 
A. Noll:

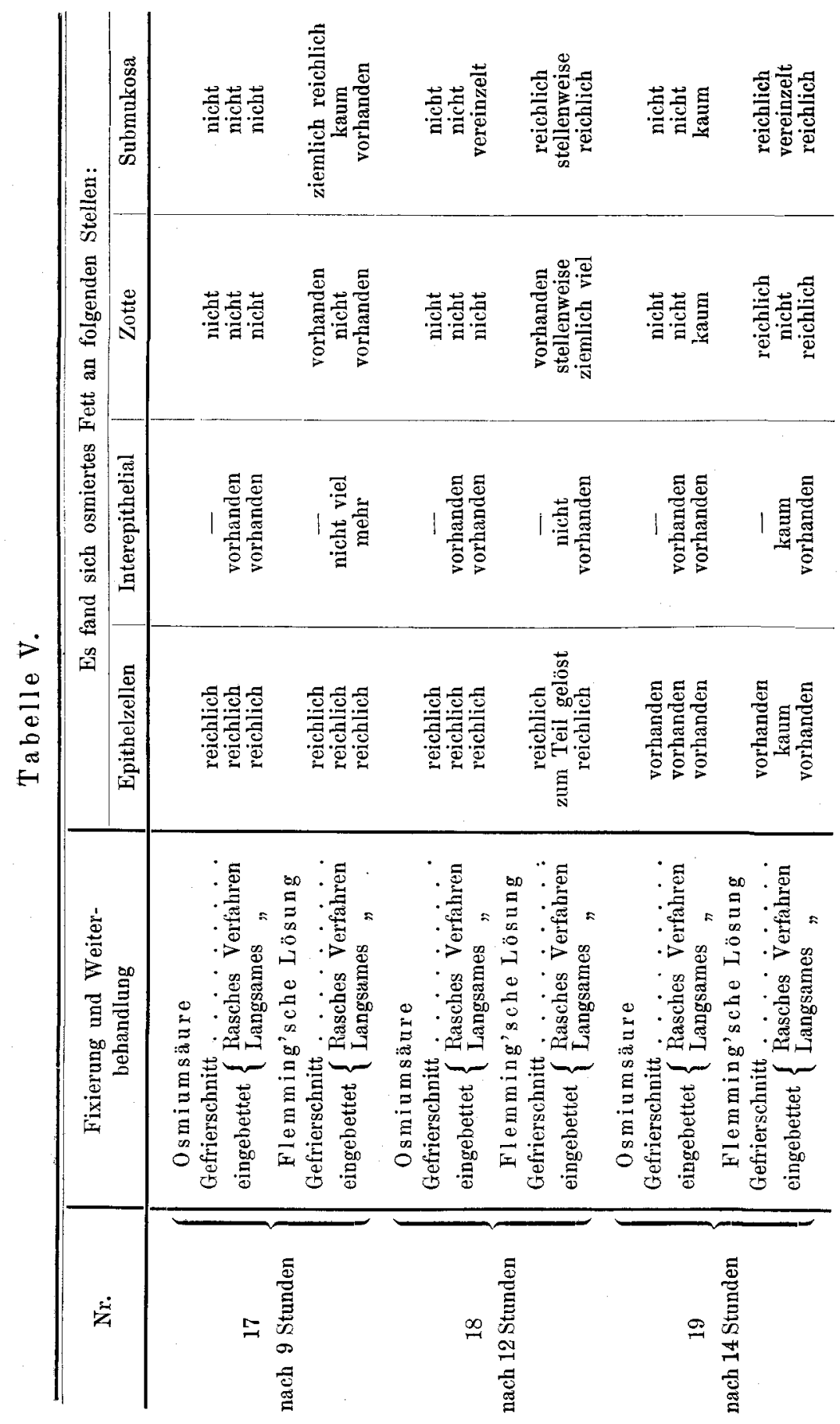


Ich hebe zunächst hervor, was die Osmiumpräparate über das Vorhandensein von Fett und Fettsäure aussagen. Die reine Osmiumsäure hat das Fett in den Epithelzellen und die interepithelialen Tröpfchen geschwärzt. Da sich an beiden Stellen die Tröpfchen bei der raschen Aikoholbehandlung haltbar zeigten, ist bewiesen, dass sie nicht aus freier Ölsäure bestehen. Hinsichtlich des Epithelfettes entspricht dies Resultat vollständig dem Ergebnis der Titrierung. Für das interepitheliale Fett war in gleicher Schärfe der Nachweis noch nicht erbracht, erst dureh das mikrochemische Verfahren ist bewiesen, dass auch es keine freie ÖIsäure ist. Was das Chylusfett anlangt, so hat auffallenderweise die Osmiumsäure überhaupt nicht oder nur ganz sehwach mit ihm reagiert ${ }^{1}$ ). Dass hierbei das Einbettungsverfahren ohne Schuld ist, lehrte die Betrachtung der Gefriersehnitte. Man würde angesichts dieser Tatsachen zu keinem Resultat kommen, wenn nicht schon durch die Titration einwandsfrei gezeigt wäre, dass im Chylus keine freie Ölsäure vorhanden sein kann. Ich verweise hierzu nochmals auf Fig. 5 auf Taf. XI, wo man die mächtige Fettanhäufung in den Bahnen der Submukosa sieht, Ölsäure aber sich in dem Extrakt verhältnismässig wenig fand. Bei dem Chylusfett entscheidet also die rein chemische Methode. Hiernach ist das Resultat dies, dass weder die in der Epithelschicht noch die in den abführenden Bahnen liegenden mikroskopisch sichtbaren Fettmassen aus freier Ölsäure bestehen.

Was lehrt andererseits der Vergleich der Flemming- und Osmiumpräparate im Hinblick auf' die Anwesenheit von Seife? Die Flemming' sche lösung hat, wie die Gefrierschnitte lehren, in der Tat im Gegensatz zur Osmiumsäure das Chylusfett geschwärzt. Man würde aber einen grossen Fehler machen, wenn man hieraus auf Seife schliessen wollte. Denn erstens weiss man ja, dass es emulgiertes Fett ist, welches die Lymphe abführt, und zweitens hat sich Seife während der Resorption nicht mehr als im nüchternen Zustand gefunden. Der Vergleich geht also hier deshalb nicht, weil die Osmiumsäure am Chylusfett überhaupt versagt. Im übrigen, speziell am Epithel, zeigt sich zwischen Flemming - und Osmiumpräparaten kein Unterschied.

1) Mar erkennt in den Lumina der Chylusgefässe den fixierten Inhalt auch da, wo die Reaktion ausgeblieben ist. Er erscheint ganz schwach getönt, geradeso wie das Blut in den Blutgefässen. 
Nun lehren aber die Flemming - Präparate in anderer Richtung etwas Neues. Bei dem raschen Alkoholverfahren nämlich wird in ihnen viel Fett gelöst, in den Chylusbahnen stellenweise alles, aber auch etwas von dem Fett zwischen den Epithelzellen und hin und wieder auch von dem Epithelfett selbst. Das kann nur auf einer Veränderung des Fettes bei der Fixierung beruhen. Vielleicht wird es unter Abspaltung von Ölsäure zerlegt. Jedenfalls ist das entstehende Produkt leichter löslich als nach Fixierung in reiner Osmiumsäure; diese Beobachtung hatte auch Fle $\mathrm{m} \mathrm{ming}^{1}$ ) selbst schon gemacht. Gleichzeitig scheint bei der Fixierung auch eine morphologische Veränc̉erung einzutreten. Darauf deuten die ungleichmässigen Formen des geschwärzten Fettes, die zum Teil mehr homogene, weniger intensiv geschwärzte Massen, zum Teil schwarze Tropfen verschiedener Grösse darstellen. Es ist möglich, dass, wie Köster meint, ein Konfluieren der Tröpfehen stattfindet.

Eine histologisch-technisch wichtige Tatsache, welche meine Versuche ergeben, ist nun die, dass man, um möglichst alles Fett zu fixieren, Osmiumlösungen verwenden muss, denen Säure, wie z. B. in der Flemming'schen Lösung, zugesetzt ist. Ich fand, dass auch der alleinige Zusatz von $1 \%$ iger Chromsäure schon wirkt, allerdings wird dann das Fett nicht so schwarz wie bei Flem mingscher Lösung. Die Altmann'sche Lösung dagegen hat an den Därmen denselben Effekt wie reine Osmiumsäure gehabt. Eine Kombination von $1 \%$ iger Osmiumlösung mit Calc. salicyl. (in Substanz bis zur Sättigung zugegeben) hatte sehr gute Resultate. Sowohl die Ausgiebigkeit der Fettdarstellung war bedeutend, als auch war bemerkenswert, wie distinkt und gleichmässig die einzelnen Tröpfchen in den abführenden Bahnen heraustreten. In Fig. 9 sieht man eine Anzahl Chylusgefässe der Submukosa mit solchen Fetttropfen gefüllt.

Somit kommeich auf Grund derindiesem Abschnitt geschilderten Befunde zu dem Ergebnis, dass das mikroskopisch nachweisbare, zumeist emulgierte Fett in der Darmschleimhaut nirgends aus freier ölsäure besteht, und dass auch Seife sich nicht oder kaum

1) Flemming, Ü̉ber die Löslichkeit des osmierten Fettes und des Myelins in Terpentinöl. Zeitschr. f. wissensch. Mikroskopie Bd. 6 S. 39 und 178. 1889. 
darin befindet. Die tatsächlich konstatierte geringe Zunahme von Ölsäure bei der Resorption ist höchstwahrscheinlich auf die Epithelzellen zu beziehen. Denn sie ist nachweisbar gerade dann, wenn das Epithel tätig ist. Im übrigen ist nur gebundene Fettsäure vorbanden. Ob aber die Bindungals Triglycerid oder in anderer Weise erfolgt, können meine Untersuchungen nicht entscheiden.

\section{Schlussbetrachtungen.}

Die Untersuchungen ergaben, dass das in die Epithelzellen eingetretene Fett zum Teil die Zellen passiert, ohne erst in Form von Tropfen aufgespeichert zu werden, zum andern Teil zunächst in den Tropfen zurückgehalten wird. Diese Tropfen sind das erste mikroskopisch sichtbare Fett. Sie bestehen gewiss nicht aus freier Fettsäure. Indem es unentschieden bleibt, ob das Triglycerid vorliegt, so steht jedenfalls fest, dass es nach Ölfütterung beim Kaninchen ein flüssiges Fett ist. Woraus sich das Fett in der Zelle bildet, ist eine Frage, die aufs engste mit der Frage zusammenhängt, in welcher Form es in die Zelle gelangt. Vollzieht sich, wie man jetzt annimmt, der Übergang in Form der Spaltungsprodukte, so würde eine Synthese in der Zelle erfolgen; dass die Epithelzellen wirklich ein weitgehendes Synthetisierungsvermögen besitzen, ist für den Frosch wenigstens erwiesen. Stellt man sich nun auf den Standpunkt, dass zunächst etwa Fettsäure in die Zelle gelangt, so wäre es begreiflich, wenn man in ihr neben dem Neutralfett immer noch etwas freie Fettsäure anträfe. Einen positiven Anhaltspunkt hierfür scheinen die oben erwähnten mikrochemischen Befunde Rossi's zu liefern. Auch in meinen Versuchen könnte der geringe Mehrgehalt an freier Fettsäure in den resorbierenden Därmen von solcher noch nicht synthetisierter Ölsäure der Epithelzellen herrühren. Wie ich aber nochmals betonen muss, würde diese O)säure im Osmiumpräparat nicht hervortreten.

Wenn man sich weiter fragt, wie das Fett aus den Zellen wieder austritt, $u m$ in das Zotteninnere zu gelangen, so hat man nach den früheren Ausführungen zwischen dem Fett der Tropfen und demjenigen zu unterscheiden, welches, wie ich mit $O$ ppel annehme, die Zelle passiert, ohne erst dort abgelagert zu werden.

Ich fasse zunächst die Tropfen ins Auge. Diese verschwinden 
erst gegen das Ende der Resorption hin und, wie es scheint, ziemlich schnell. In dieser Phase ist keine Zunahme freier Fettsä́ure in der Schleimhaut nachweisbar. Daraus folgt, dass dieses Fett vordem Austritt nicht erst gespalten und als Fettsäure weitergegebeu wird, sondern dass es als Neutralfett, und zwar, da sich in Übereinstimmung mit den bisherigen Erfahrungen niemals austretende Tröpfehen als solche nachweisen liessen, als gelöstes Fett die Zelle verlässt. Erst nach dem Austritt findet es sich zwischen den Epithelzellen wieder in Form mehr oder weniger distinkter Tröpfchen. Die Ansammlung der Tropfen innerhalb der Zellen erklärt sich als eine Folge übermässigen Fettgehalts des Protoplasmas bei reichlicher Fettzufuhr. Welche Rolle bei diesem Vorgang die Zell granula spielen, soll hier nicht erörtert werden ${ }^{1}$ ). Man muss jedenfalls annehmen, dass schon im Protoplasma, wenn auch vielleicht nicht auschliesslich dort, eine Synthese erfolgt. Hierbei würde dem Protoplasma der Darmepithelzellen eine aktive Tätigkeit zufallen, wie demjenigen vieler Drüsenzellen, wo die Ausarbeitung der in den Sekrettropfen enthaltenen spezifischen Produkte Aufgabe des Protoplasmas ist.

Ähnlich verhält es sich mit dem Fett, welches die Zellen passiert, ohne dort erst abgeschieden zu werden. Da das Synthetisierungsvermögen der Zellen erwiesen ist, ist es von vornheręin am wahrscheinlichsten, dass auch dieses Fett Neutralfett, $\mathrm{r}$. h. irgeudwie gebundene Fettsäure ist. Einen tatsächlichen Beweis gegen die Annahme Oppel's, wonach die Spaltungsprodukte des Darminhalts unverändert die Zellen passieren sollen, sehe ich darin, dass niemals solche Mengen freier Fettsäure oder Seife in der Darmschleimhaut nachweisbar waren, wie man entsprechend der Annahme Oppel's erwarten solite.

$\mathrm{Z}$ wischen den Epithelzellen trifft man wohl nur solches Fett an, welches aus den Tropfen der Epithelzellen stammt. Ob dies interepitheliale Fett schon vor der Fixierung dort lag oder nach der Herausnahme des Darmes rückläufig hingekommen ist, ist hier nicht die wesentliche Frage. Jedenfalls ist es das nächste sichtbare Fett auf dem Transportweg. Ich habe aber Grund zu der Annahme, dass

1) Vgl. hierzu die Auseinandersetzungen M. Heidenhain's in "Plasma und Zelle". v. Bardeleben's Handb. S. $421 \mathrm{ff}$. 
es nicht zurückgestaut ist; denn es zeigt den charakteristischen Unterschied zu dem Chylusfett, dass es von $1 \%$ Osmiumlösung geschwärzt wird, jenes aber nicht oder nur unvollkommen. Dies dürfte nicht der Fall sein, wenn es einfach zurückgetriebener Chylus wäre. Auch dieses Fett stellt gebundene Fettsäure dar, und es sind keine Merkmale dafür vorhanden, dass es andere Zusammensetzung hätte als das Epithelfett.

Schwieriger ist die Beurteilung des Chylusfettes. Man kann mit Bestimmtheit sagen, dass es bauptsächlich oder ausschliesslich aus dem Fett stammt, welches die Epithelzellen passiert hat, sei es, dass das letztere dort erst abgeschieden war oder nicht. Ebenso sicher ist es, dass es auch keine freie Fettsäure ist. Fs zeigt aber die vorläufig noch unerklärte Eigentümlichkeit, sich im Gegensatz zu dem übrigen Fett nicht direkt mit Osmiumsäure zu schwärzen. Darf man hieraus schliessen, dass es chemisch anders zusammengesetzt ist als jenes?

Allem Anschein nach haben wir es im Chylus mit einer besonderen Form der Fettemulsion zu tun. Der Chylus des Duct. thoracicus vom Hund enthält bekanntlich die Fetttröpfehen in äusserst feiner "staubartiger" Verteilung. v. Frey ${ }^{1}$ ) bestimmte ihre Grösse noch unter $1 / 2 \mu$. Das sind physikalische Verhältnisse, wie sie sich nach v. Frey in einer Schüttelemulsion von neutralem Öl in destilliertem Wasser künstlich nicht herstellen lassen, und nach v. Frey mit ein Grund für die auffallende Bestandigkeit der Chylusemulsion. Über das Aussehen des frischen Chylus der Darmgefässe ist bislang nichts bekannt. Ich selbst habe in dem frisch entleerten Chylus der mesenterialen Gefässe eines meiner Kaninchen diese äusserst feine Emnlsion ebenfalls sehen können und nehme an, dass auch schon in der Darmschleimhaut der Chylus das gleiche Aussehen hat. Es wäre möglich, dass diese staubartige Fmulsion aus physikalischen Gründen die Osmiumfärbung verhindert. Unwahrscheinlich ist es mir, dass die Tröpfehen von irgendeiner Hülle umgeben sind, welche erst durch gewisse Zusätze zur Osmiumsäure, wie z. B. Essigsäure, zerlegt werden müssten, damit die Osmiumsäure an die Tropfen heran kann. Jedenfalls lässt sich bei meinen Versuchen eine Seifenhülle ausschliessen, weil sich die erforderliche Seife gar

1) v. Frey, Die Emulsion des Fettes im Chylus. Arch. f. (Anat. u.) Physiol. 1881 S. 382. 
nicht hat nachweisen lassen. Um zu einer klaren Kenntnis der Chylusbeschaffenbeit zu kommen, sind weitere Untersuchungen unbedingt nötig. Einstweilen wird man angesichts soleher oder anderer Möglichkeiten aus demeigenartigen Verhalten der Osmiumsäure noch nicht folgern dürfen, dass das Ohylusfett eine anderechemische Zusammensetzung habe als das Epithelfett. Es muss daher vorläufig unentschieden bleiben, ob etwa das Fett auf dem Wege vom Epithel in die Chylusgefässe eine chemische Veränderung erleidet.

Die bisherigen Betrachtungen bezogen sich ausschliesslich auf diejenigen Fälle, in denen, wie bei meinen Versuchen, sehr viel Fett verfüttert wird. Hält sich die Fettzufuhr in natürlichen Grenzen, so kommt es nach den bisherigen Erfahrungen einiger Autoren nicht zu der starken Anhäufung von Fetttropfen im Epithel. Der Vorgang in den Epithelzellen vereinfacht sich dann insofern, als in ihnen nun vorwiegend die mit der Osmiummethode nicht nachweisbaren Vorgänge der Verarbeitung und sofortigen Weiterbeförderung des aufgenommenen Fettes ablaufen. $\mathrm{Ob}$ auch in diesen Fällen die Rolle der Chylusbahnen bei dem Transport eine so grosse und augenfällige ist, scheint mir fraglich. Stickel ${ }^{1}$ ) hat wenigstens bei saugenden Hündehen und neugeborenen Kindern das charakteristische milchigweisse Aussehen der Chylusgefässe nur selten gefunden.

So komme ich zum Schluss auf die Frage, ob nicht Fett noch anders als in Form der Emulsion und auf anderem Wege als durch die Chylusbahn aus dem Darm abgeführt wird. Wie zuerst die Versuche Zawilski's ${ }^{2}$ ) zeigten, findet sich im Chylus nicht alles verfütterte Fett wieder. Es ist möglich, dass sich auch die Blutbahn bei dem Transport beteiligt. Auch meine Versuche weisen darauf hin, dass die Lymphbahn nicht den einzigen Abführweg darstellt. Fs ist nämlich zu auffallend, dass bei den Kaninchen erst in der fünften Verdauungsstunde der Chylus deutlich fetthaltig war, trotzdem sich bis dahin in den Epithelzellen schon viel Fett angesammelt hatte. Schlägt das Fett vielleicht zunächst einen anderen Weg ein und kommt erst dann in die Chylusbahn, wenn die resorbierte Menge eine gewisse Grenze überschreitet?

1) Die Arbeit erscheint im Arch. f. Gynäkol.

2) Zawilski, Dauer und Umfang des Fettstromes durch den Brustgang nach Fettgenuss. Arbeiten der physiol. Anstalt zu Leipzig, 11. Jahrg., 1876 S. 147. 
Chem. und mikroskop. Untersuchungen über den Fetttransport etc. 247

Nach allem, was meine Untersuchungen lehren, komme ich zu der Überzeugung, dass die mikroskopisch nachweisbaren Vorgänge bei der Fettresorption nur einen Teil des gesamten Vorganges darstellen.

\section{Erklärung der Abbildungen auf Tafel XI und XII.}

Dünndarm des Kaninchens während der Resorption von Öl.

Fig. 1-4. Mikrophotogramme nach ungefärbten Flemming-Präparaten. Vergr. 110. Man sieht das osmierte Fett in frühen Stadien nur im Epithel (Fig. 1 und 2), später auf dem Transport durch das Zottenstroma in das zentrale Chylusgefäss (Fig. 3 und 4). Genauere Beschreibung Text S. 224.

Fig. 5. Mikrophotogramm. Fixierung in Formol, Färbung mit Sudan III. Vergr. 60. 12 Stunden nach der Eingabe des Öls. Viel Fett in den Chylusgefässen der Submukosa. (Vgl. Text S. 224.)

Fig. 6. Eine Zotte aus Fig. 3 bei 170 facher Vergrösserung gezeichnet. (Text S. 224.)

Fig. 7. Eine schräg durchschnittene Zotte vom nämlichen Fall wie Fig. 4, gezeichnet. Ungefärbtes Fl emming-Präparat. Vergr. 230. (Text S. 224.)

Fig. 8. Querdurchschnittene Zottenepithelien. 1\% ige Osmiumlösung. Keine Färbung. Vergr. 580. Interepitheliales Fett.

Fig. 9. Aus der Submukosa. Fixierung mit $1 \%$ iger Osmiumsäure + Calc. salicyl. Vergr. 140. (Vgl. Text S. 242.) 